Supporting Information

\title{
HygY is a Twitch Radical SAM Epimerase with Latent Dehydrogenase Activity Revealed upon Mutation of a Single Cysteine Residue
}

\author{
Ronald A. Besandre, ${ }^{1}$ Zhang Chen, ${ }^{1}$ Ian Davis, ${ }^{2}$ Jiawei Zhang, ${ }^{1}$ \\ Mark Walter Ruszczycky, ${ }^{3}$ Aimin Liu, ${ }^{2}$ and Hung-wen Liu*1,3 \\ ${ }^{1}$ Department of Chemistry, University of Texas at Austin, Austin, Tx 78712, United States \\ ${ }^{2}$ Department of Chemistry, University of Texas at San Antonio, San Antonio, Tx 78249, United States \\ ${ }^{3}$ Division of Chemical Biology and Medicinal Chemistry, College of Pharmacy, University of Texas at \\ Austin, Austin, Tx 78712, United States
}

\section{Table of Contents}

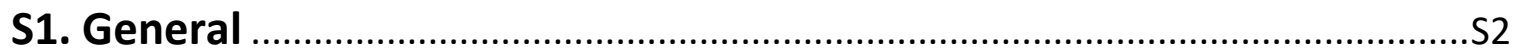

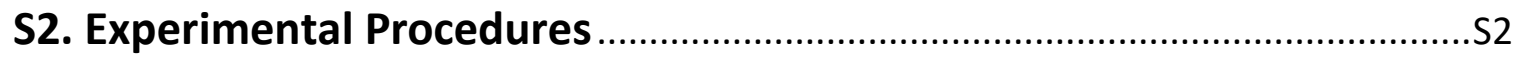

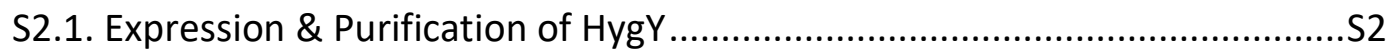

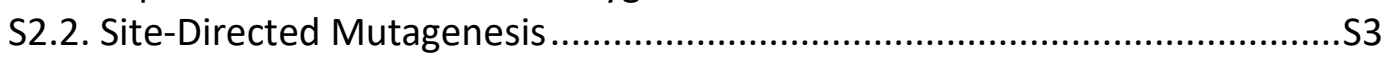

S2.3. Iron-Sulfur Reconstitution of Wild-Type \& Mutant HygY ..........................S4

S2.4. EPR Sample Preparation \& Analysis ............................................................S5

S2.5. Reaction of HygY Wild-Type \& Cys183Ala Mutant ......................................S5

S2.6. Reaction of HygY Wild-Type \& Cys183Ala Mutant in Buffered $\mathrm{D}_{2} \mathrm{O}$.............S6

S2.7. Isolation of HygY Enzymatic Product 8 (Derivatized to 18) .........................S6

S2.8. Determination of HygY Wild-Type and Cys183Ala Specific Activities...........S7

S2.9. Synthesis of Glycosyl Acceptor and Donors ...........................................S8

S2.10. Synthesis of Pseudodisaccharides.......................................................S10

S2.11. Synthesis of Derivatized Pseudodisaccharide Standards.......................S14

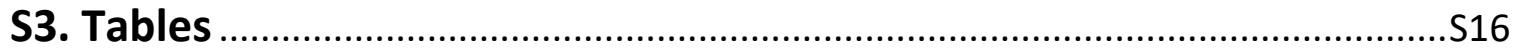

Table S1. Forward and reverse primers for site-directed mutagenesis .............S16

Table S2. NMR assignment of the derivatized HygY reaction product................S16

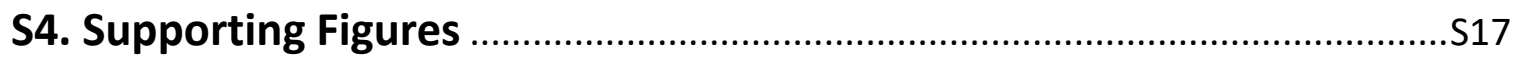

Figure S1. UV/Vis spectra \& SDS-PAGE of HygY Wild-TypeT \& Mutants .............S17

Figure S2. Sequence alignment of HygY, NeoN, and BtrN ..............................S18

Figure S3. HSQC spectrum (zoom, ring region) of isolated 18 from HygY...........S19

Figure S4. HMBC spectrum (zoom, ring region) of isolated 18 from HygY..........S2O

Figure S5. LC-MS analysis of HygY reaction with 7D .....................................S21

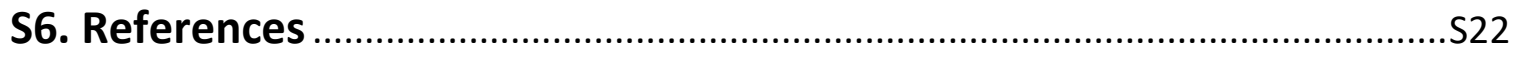

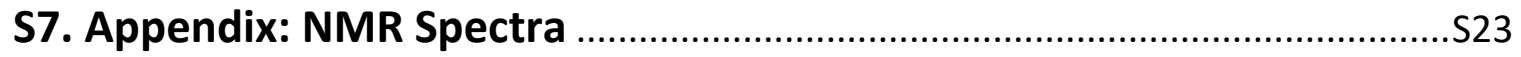




\section{S1. General}

All chemicals and reagents were purchased from Fisher Scientific (Pittsburgh, PA) or SigmaAldrich (St. Louis, MO) and were used without further purification unless otherwise specified. Tetrahydrofuran was distilled with sodium under argon. Dichloromethane was dried over anhydrous $\mathrm{CaCl}_{2}$ and distilled. All other dry solvents were purchased from either Fisher Scientific or Sigma-Aldrich and used directly. NMR spectra were recorded on a Varian DirectDrive $400 \mathrm{MHz}$ spectrometer or a Bruker Avance III HD $500 \mathrm{MHz}$ spectrometer equipped with a BBFO Prodigy CryoProbe at the NMR Facility in the Department of Chemistry, University of Texas at Austin. ${ }^{13} \mathrm{C}$ spectra were recorded with proton broadband decoupling. Deuterated solvents were used as internal standards in the NMR spectra. EPR spectra were obtained on a Bruker E560 X-band spectrometer equipped with a cryogen-free $4 \mathrm{~K}$ temperature system and an SHQE high-Q resonator at the University of Texas at San Antonio. Glassware was flame-dried under vacuum and refilled with argon for chemical reactions. Silica gel column chromatography was carried out using SiliaFlash P60 (230-400 mesh, Silicycle). LC-ESI-MS analysis was performed under an Agilent Technologies HPLC system equipped with a pump (G1311C), an auto sampler (G1329B), and a ToF mass spectrometer (G6230B) with an electrospray ionization (ESI) source. Anaerobic assay conditions were achieved using a Coy vinyl anaerobic chamber under an atmosphere of $98.5 \%$ $\mathrm{N}_{2}, 1.5 \% \mathrm{H}_{2}$ and less than $20 \mathrm{ppm} \mathrm{O}_{2}$. The hygromycin B producing strain Streptomyces hygroscopicus, subsp. hygroscopicus was obtained from the American Type of Culture Collection (ATCC). The pRKSUF017 plasmid ${ }^{1}$ was kindly provided by Professor Tadashi Eguchi of the Tokyo Institute of Technology.

\section{S2. Experimental Procedures}

\section{S2.1. Expression \& Purification of $\mathrm{HygY}$}

The hygY gene was amplified by PCR with primers HygY-F (5'-GCTGATATCGGATCCGAATT CATGAGTTATGGCCTCGTCGAC-3') and HygY-R (5'-CTGCGGGTGGCTCCATGCTGAGAACCTCTTTCCC TGGGCGTA-3') using genomic DNA extracted from Streptomyces hygroscopicus, subsp. hygroscopicus, which possesses the hygromycin B biosynthetic gene cluster. This PCR product was then used as the template and amplified by PCR with HygY-F and twinstrep-adaptor-R (5'- 


\section{CTCGAGTGCGGCCGCAAGCTTTCATTTTTCGAACTGCGGGTGGCTCCATGCTGATCCTCCTGATCCTCCT}

CCTGATCCTCCTCCTTTTTTCGAACTGCGGGTGGCTCCATGCTGA-3'). The resulting PCR product was inserted into pET30a (Novagen) at EcoRI \& HindIII by Gibson assembly to form plasmid pET30aHygY-twinstrep, and its sequence was confirmed by sequencing using T7 universal primers.

Plasmid pET30a-HygY-twinstrep was introduced into E. coli BL21(DE3) containing pRKSUF017 ${ }^{1}$ in the presence of $30 \mu \mathrm{g} / \mathrm{mL}$ of kanamycin and $5 \mu \mathrm{g} / \mathrm{mL}$ of tetracycline for Hyg protein expression. E. coli BL21(DE3) containing both pET30a-HygY-twinstrep and pRKSUF017 was agitated at $200 \mathrm{rpm}$ in $2.8 \mathrm{~L}$ Fernbach flasks containing $30 \mu \mathrm{g} / \mathrm{mL}$ of kanamycin and $5 \mu \mathrm{g} / \mathrm{mL}$ of tetracycline in $12 \mathrm{LB}$ media at $37^{\circ} \mathrm{C}$ until the $\mathrm{OD}_{600}$ reached 0.5 . Expression was initiated by the addition of $200 \mu \mathrm{M} F\left(\mathrm{NH}_{4}\right)_{2}\left(\mathrm{SO}_{4}\right)_{2}, 200 \mu \mathrm{M}$ L-cysteine, and $100 \mu \mathrm{M}$ isopropyl $\beta$-Dthiogalactopyranoside (IPTG). The cells were agitated at $80 \mathrm{rpm}$ and $18{ }^{\circ} \mathrm{C}$ for an additional $18-$ 20 hours and then harvested by centrifugation at 4,000 $\mathrm{g}$. The cells were then collected, suspended in cold buffer A (50 mM HEPES, $300 \mathrm{mM} \mathrm{NaCl}, 20 \%$ gylcerol, pH 8.0) containing 10 $\mathrm{mM}$ imidazole, and disrupted by sonication for 10 seconds with 20 second rest intervals ( 5 min total sonication time). Centrifugation of the sonicated mixture at $13,000 \mathrm{~g}$ for $1 \mathrm{~h}$ at $4 \mathrm{C}$ gave a cloudy, brown supernatant that was gently rocked with $3 \mathrm{~mL} \mathrm{Ni-NTA}$ agarose resin (Qiagen) for $1 \mathrm{~h}$ at $4 \mathrm{C}$ before transfer of the resin-containing supernatant onto an empty column. The flow through was discarded, and the column was washed with $10 \mathrm{~mL}$ buffer B (buffer A containing 20 $\mathrm{mM}$ imidazole) to remove weakly-binding proteins. HygY was eluted with $12.5 \mathrm{~mL}$ of buffer $\mathrm{C}$ (buffer A containing $250 \mathrm{mM}$ imidazole). The dark brown protein solution was gently rocked with $1 \mathrm{~mL}$ of buffer-equilibrated Strep-Tactin XT resin (IBA Lifesciences) for $1 \mathrm{~min}$ at $4 \mathrm{C}$ before transfer of the mixture onto an empty column. The flow through was discarded, and the column was washed with $10 \mathrm{~mL}$ storage buffer (50 mM HEPES, $150 \mathrm{mM} \mathrm{NaCl}, 20 \%$ glycerol, pH 7.4) to remove nonspecific binding proteins. HygY was eluted with $10 \mathrm{~mL}$ of storage buffer containing $50 \mathrm{mM}$ biotin. The sepia-colored protein was diafiltrated with fresh storage buffer (Amicon Ultra-15, 10 $\mathrm{kDa} \mathrm{MWCO}$ ) to remove biotin, flash frozen in liquid $\mathrm{N}_{2}$, and stored at $-80^{\circ} \mathrm{C}$ until use.

\section{S2.2. Site-Directed Mutagenesis}


The plasmid pET30a-HygY-twinstrep was used as the template for site-directed mutagenesis via three-fragment Gibson assembly. For pET30a-HygY-C24A/C28A/C31A-twinstrep construction (i.e., $\Delta$ cat-HygY), fragment HygY-C24A/C28A/C31A-left was obtained by PCR with HygY-F and HygY-C24A/C28A/C31A-R using plasmid pET30a-HygY-twinstrep as the template. Fragment HygYC24A/C28A/C31A-right was obtained by PCR with HygY-C24A/C28A/C31A-F and HygY-R using plasmid pET30a-HygY-twinstrep as the template followed by a second PCR with HygYC24A/C28A/C31A-F and twinstrep-adaptor-R. The plasmid pET30a-HygY-C24A/C28A/C31Atwinstrep was then obtained using Gibson assembly with pET30a digested by EcoRI \& HindIII, HygY-C24A/C28A/C31A-left, and HygY-C24A/C28A/C31A-right.

For pET30a-HygY-C183A-twinstrep construction, fragment HygY-C183A-left was obtained by PCR with HygY-F and HygY-C183A-R using plasmid pET30a-HygY-twinstrep as the template. Fragment HygY-C183A-right was obtained by PCR with HygY-C183A-F and HygY-R using plasmid pET30a-HygY-twinstrep as the template followed by a second PCR with HygY-C183A-F and twinstrep-adaptor-R. The plasmid pET30a-HygY-C183A-twinstrep was then obtained using Gibson assembly with pET30a digested by EcoRI \& HindIII, HygY-C183A-left and HygY-C183A-right. The sequence of each hygY mutant was confirmed by sequencing using T7 universal primers. The resulting plasmids were introduced into pRKSUF017-containing E. coli BL21(DE3). The mutant proteins were overexpressed and purified in the same manner as the wild-type enzyme.

\section{S2.3. Iron-Sulfur Reconstitution of Wild-Type \& Mutant HygY}

Wild-type HygY was found to contain $5.2 \pm 0.4$ and $5.8 \pm 1.5$ iron and sulfide, respectively, per mole monomer prior to reconstitution. The $\Delta$ cat-HygY mutant was found to contain $4.6 \pm 0.2$ and $3.1 \pm 0.7 \mathrm{~mol}$ iron and sulfide, respectively, per mole monomer prior to reconstitution. Therefore, isolated enzyme preparations were treated as follows in order to standardize $\left[\mathrm{Fe}_{4} \mathrm{~S}_{4}\right]$ reconstitution. An aliquot of wild-type or mutant HygY from frozen stock was brought into the anaerobic chamber, thawed, kept at $4 \mathrm{C}$, and diluted with $25.0 \mathrm{mM}$ HEPES (pH 7.4) containing $300 \mathrm{mM} \mathrm{NaCl}, 1.0 \mathrm{mM}$ DTT, and 10\% glycerol. A 10-fold equivalent of ammonium iron(II) sulfate hexahydrate was added over a period of 10 minutes, followed by addition of sodium sulfide (10fold equivalent) over a period of 20 minutes. After a $2 \mathrm{~h}$ incubation at $4 \mathrm{C}$, the reconstitution 
mixture was desalted twice using centrifugal filtration (diafiltration, 10 kDa MWCO Amicon Ultra$0.5 \mathrm{~mL}$ ) and the aforementioned buffer.

\section{S2.4. EPR Sample Preparation \& Analysis}

An aliquot of enzyme from the frozen stock was thawed, freshly reconstituted as described in Section S2.3 and concentrated to ca. $200 \mu \mathrm{L}$ ( $250 \mu \mathrm{M}$ solution) via centrifugal filtration with a 10 kDa MWCO Amicon Ultra-0.5 mL filter unit. Ten equivalents of sodium dithionite were added to reduce the enzyme, the resulting solution was transferred to a $3 \mathrm{~mm}$-ID quartz EPR tube, and incubated for $5 \mathrm{~min}$ at room temperature prior to freezing in cryogenic isopentane. Samples were taken out of the glove box and stored in a liquid nitrogen dewar until analysis by EPR.

The X-band $(9.37 \mathrm{GHz}$ ) continuous-wave (CW) EPR spectra were recorded on a Bruker E560 Xband continuous-wave spectrometer equipped with a cryogen-free $4 \mathrm{~K}$ temperature system and an SHQE high-Q resonator at the University of Texas at San Antonio. The instrument parameters were as follows: temperature: 10-40 K, microwave power: $12.6 \mathrm{~mW}$, modulation amplitude: 1.0 $\mathrm{mT}$, modulation frequency: $100 \mathrm{kHz}$, conversion time: $44 \mathrm{~ms}$. Spectra were simulated using the pepper function in the EasySpin MATLAB package. ${ }^{2}$

\section{S2.5. Reaction of HygY Wild-Type \& Cys183Ala Mutant}

HygY was freshly reconstituted prior to each reaction assay. Freshly reconstituted HygY or Cys183Ala mutant $(25 \mu \mathrm{M})$ was incubated with $250 \mu \mathrm{M}$ substrate (7 or 7D), $500 \mu \mathrm{M}$ SAM, 500 $\mu \mathrm{M}$ sodium dithionite in $25.0 \mathrm{mM}$ HEPES (pH 7.4) containing $300 \mathrm{mM} \mathrm{NaCl}, 1.0 \mathrm{mM}$ DTT, and $10 \%$ glycerol (total volume of $200 \mu \mathrm{L}$ ) for $12 \mathrm{~h}$ at room temperature. The enzyme was removed via centrifugal filtration (10 kDa MWCO YM-10 filter, Millipore) to quench the reaction. An aliquot of the filtrate $(10 \mu \mathrm{L})$ was analyzed directly via positive ion ESI LC-MS using a CAPCELL CORE AQ column $(2.7 \mu \mathrm{m}, 4.6 \times 150 \mathrm{~mm}$, Osaka Soda). Liquid chromatography used a flow rate of 0.4 $\mathrm{mL} / \mathrm{min}$ with $100 \%$ of $0.1 \%$ formic acid in water for $5 \mathrm{~min}$ followed by a linear gradient to $90 \%$ acetonitrile in $20 \mathrm{~min}$. The $\mathrm{m} / \mathrm{z}$ for the substrates/epimers, $2^{\prime}$-keto product, and $5^{\prime}$-dAdo were monitored (calcd. for $\mathrm{C}_{12} \mathrm{H}_{24} \mathrm{~N}_{2} \mathrm{O}_{8}[M+\mathrm{H}]^{+}=325.1611,7 / 8$; calcd. for $\mathrm{C}_{12} \mathrm{H}_{23} \mathrm{DN}_{2} \mathrm{O}_{8}[M+\mathrm{H}]^{+}=$ 
326.1674, 7D; calcd. for $\mathrm{C}_{12} \mathrm{H}_{22} \mathrm{~N}_{2} \mathrm{O}_{8}[M+\mathrm{H}]^{+}=323.1454$, 19; calcd. for $\mathrm{C}_{10} \mathrm{H}_{13} \mathrm{~N}_{5} \mathrm{O}_{3}[M+\mathrm{H}]^{+}=$ 252.1096, 15; calculated for $\mathrm{C}_{10} \mathrm{H}_{12} \mathrm{DN}_{5} \mathrm{O}_{3}[M+\mathrm{H}]^{+}=253.1160$, monodeuterated 15).

The remainder of the reaction filtrate was combined with $15 \mu \mathrm{L}$ saturated $\mathrm{NaHCO}_{3}$ and incubated for $12 \mathrm{~h}$ with $50 \mu \mathrm{L}$ of $100 \mathrm{mM}$ benzyl chloroformate in acetone. The solution was flash frozen in liquid $\mathrm{N}_{2}$ and lyophilized to give an oily residue that was suspended in $1.5 \mathrm{~mL}$ of a 1:1 solution of pyridine and acetic anhydride and then stirred for $12 \mathrm{~h}$. The derivatization mixture was subsequently concentrated in vacuo to yield a white residue that was dissolved in $\mathrm{MeOH}$ and analyzed by the same ESI-LC-MS conditions described above. In a separate experiment involving the Cys183Ala mutant and 7, the reaction mixture following the $12 \mathrm{~h}$ incubation was first treated with $50 \mu \mathrm{L}$ of $100 \mathrm{mM} \mathrm{NaBH}_{4}$ for 30 min before derivatization with benzyl chloroformate and acetic anhydride as described above. The $\mathrm{m} / \mathrm{z}$ of the derivatized substrate/epimer and 2'-keto product were monitored (calculated for $\mathrm{C}_{40} \mathrm{H}_{48} \mathrm{~N}_{2} \mathrm{O}_{18}[M+\mathrm{H}]^{+}=845.2981,17 / 18$; calculated for $\mathrm{C}_{40} \mathrm{H}_{47} \mathrm{DN}_{2} \mathrm{O}_{18}[\mathrm{M}+\mathrm{H}]^{+}=846.3044,18 \mathrm{D}$; calculated for $\left.\mathrm{C}_{38} \mathrm{H}_{44} \mathrm{~N}_{2} \mathrm{O}_{17}\left[M+\mathrm{NH}_{4}\right]^{+}=818.2985,20\right)$.

\section{S2.6. Reaction of HygY Wild-Type \& Cys183Ala Mutant in Buffered $D_{2} \mathrm{O}$}

Buffered $\mathrm{D}_{2} \mathrm{O}$ was prepared by lyophilization of the $25.0 \mathrm{mM}$ HEPES (pH 7.4) buffer containing $300 \mathrm{mM} \mathrm{NaCl}, 1.0 \mathrm{mM}$ DTT, and 10\% glycerol followed by rehydration with $\mathrm{D}_{2} \mathrm{O}$ repeated once. The deuterium enrichment was approximately $95 \%$ following $\mathrm{pH}$ adjustments with $1 \mathrm{M} \mathrm{NaOH}$ (pD = 7.7). Freshly reconstituted HygY in the standard buffer was exchanged with $\mathrm{D}_{2} \mathrm{O}$ buffer three times using centrifugal filtration with a $10 \mathrm{kDa}$ MWCO Amicon Ultra-0.5 mL filter unit. The enzyme concentrate was diluted to $25 \mu \mathrm{M}$ using $\mathrm{D}_{2} \mathrm{O}$ buffer, and the assay, derivatization, and analysis were conducted as described in Section S2.5. The reaction was monitored using LC-MS of the epimers and their derivatized counterparts (calcd. for $\mathrm{C}_{12} \mathrm{H}_{24} \mathrm{DN}_{2} \mathrm{O}_{8}[M+\mathrm{H}]^{+}=326.1674$, 8D; calcd. for $\left.\mathrm{C}_{40} \mathrm{H}_{48} \mathrm{DN}_{2} \mathrm{O}_{18}[M+\mathrm{H}]^{+}=846.3044,18 \mathrm{D}\right)$.

\section{S2.7. Isolation of HygY Enzymatic Product 8 (Derivatized to 18)}

To isolate enough epimerized product for NMR characterization, the enzymatic reaction detailed in Section S2.5 was carried out on a 50-fold larger scale (total volume of $10 \mathrm{~mL}$ ). Following a $12 \mathrm{~h}$ reaction with gentle stirring at room temperature in the anaerobic chamber, the flask containing 
the reaction mixture was removed from the glove box and centrifuged to pellet protein. The resulting supernatant was subjected to Cbz-derivatization by the addition of $750 \mu \mathrm{L}$ saturated $\mathrm{NaHCO}_{3}$ and $2.5 \mathrm{~mL}$ of a $100 \mathrm{mM}$ solution of benzyl chloroformate in acetone. The mixture was stirred for $12 \mathrm{~h}$, partially concentrated in vacuo to remove the acetone, and freeze-dried to give an oily residue that was suspended in $80 \mathrm{~mL}$ of a 1:1 solution of pyridine and acetic anhydride and stirred for an additional $12 \mathrm{~h}$. Following peracetylation, the reaction mixture was concentrated in vacuo to give a residue that was partitioned between EtOAc and water. The organic layer was washed twice with water and brine, dried with $\mathrm{Na}_{2} \mathrm{SO}_{4}$, and concentrated in vacuo. The crude product was then purified by silica gel flash chromatography (60:40 EtOAc:hexanes) to give ca. $0.5 \mathrm{mg}$ of 18. NMR Spectra $\left({ }^{1} \mathrm{H},{ }^{13} \mathrm{C}, \mathrm{HSQC}\right.$, and $\left.\mathrm{HMBC}\right)$ and peak assignments are shown in Table S2, Figures S3 \& S4, and the appendix.

\section{S2.8. Determination of HygY Wild-Type and Cys183Ala Specific Activities}

The galacamine substrate concentration was standardized by ${ }^{1} \mathrm{H} N \mathrm{NM}\left(\mathrm{D}_{2} \mathrm{O}, 500 \mathrm{MHz}\right)$ using an adenosine monophosphate (AMP) internal standard, the concentration of which was determined by UV absorbance at $260 \mathrm{~nm}\left(\varepsilon_{260}=15100 \mathrm{M}^{-1} \mathrm{~cm}^{-1}\right)$. All assays were run anaerobically in 25.0 mM HEPES (pH 7.4, $\mathrm{H}_{2} \mathrm{O}$ ) containing $500 \mu \mathrm{M}$ substrate, 1 mM DTT, 1 mM Na $2 \mathrm{~S}_{2} \mathrm{O}_{4}, 500 \mu \mathrm{M} \mathrm{SAM}$, and either $5 \mu \mathrm{M}$ HygY wild-type or Cys183Ala mutant in a total volume of $125 \mu \mathrm{L}$. These conditions were found to be near-saturating. The assays were run in triplicate, initiated by the addition of enzyme, and quenched $0,5,10,20,30$, and 120 min later by adding a $20 \mu \mathrm{L}$ aliquot of the reaction mixture to $80 \mu \mathrm{L}$ of $15 \mathrm{mM}$ aqueous $\mathrm{H}_{2} \mathrm{O}_{2}$. The resulting mixtures were removed from the anaerobic chamber, deproteinized by centrifugal filtration using Millipore 10 kDa MWCO YM-10 centrifugal filters, and analyzed by LC-ESI-MS. Extracted ion chromatograms were monitored at $\mathrm{m} / \mathrm{z} 325.1539$ (galacamine, 7) and 323.1371 (C2'-ketone, 19), while the UV absorbance was simultaneously monitored at $260 \mathrm{~nm}$. MS data was analyzed using the MassHunter software (Agilent Technologies). The fraction of reaction with respect to SAM was determined from the UV absorbance peak areas for residual SAM and 5'-dAdo, which have the same adenine chromophore. Ionization of $\mathbf{7}$ in the ESI-MS was found to be ca. 2.8 fold greater than the ketone 19 based on reactions run to near-completion. This difference in relative 
ionization efficiencies was used to correct the integrated EIC peak areas for $\mathbf{7}$ versus 19 and thus obtain a fraction of reaction with respect to the dehydrogenation of $\mathbf{7}$. Fractions of reaction below $10 \%$ (at least two data points in each trial) were used to determine the initial rate of turnover of $\mathbf{7}$ and SAM. Division of the averaged rates by the total HygY monomer concentration furnished the specific activity versus each substrate.

\section{S2.9. Synthesis of Glycosyl Acceptor and Donors}

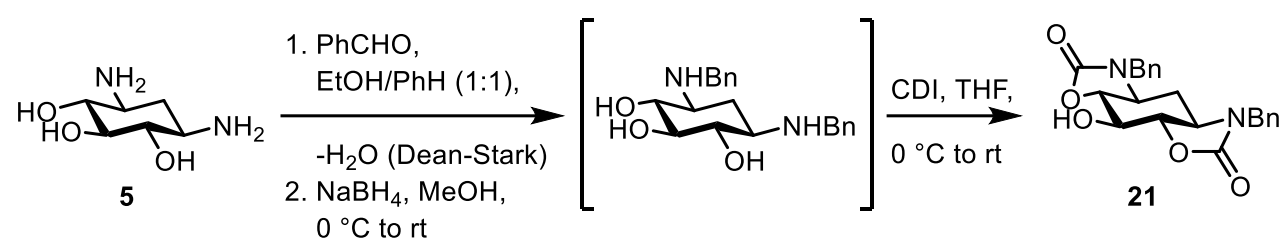

\section{Glycosyl Acceptor: $N^{1}, N^{3}$-dibenzyl- $N^{1}, O^{6} ; N^{3}, O^{4}$-dicarbonyl-2-deoxy-streptamine (21)}

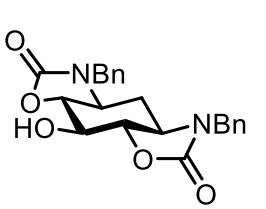

A flame-dried two-neck round-bottom flask containing 2-deoxystreptamine ${ }^{3}$ (5.0 grams, 30.9 mmol) was affixed to a Dean-Stark apparatus. Equal volumes of anhydrous ethanol and benzene (150 $\mathrm{mL}$ each) were added, followed by addition of benzaldehyde $(7.85 \mathrm{~mL}, 76.9 \mathrm{mmol})$. The mixture was allowed to stir under reflux overnight. The solution was then cooled to $0 \mathrm{C}$, upon which sodium borohydride (3.5 grams, 92.5 mmol) was added. After $45 \mathrm{~min}$, the solution was concentrated in vacuo to give a residue that was dissolved in $1 \mathrm{M} \mathrm{HCl}$ and washed twice with dichloromethane (DCM). The aqueous layer was then basified to ca. $\mathrm{pH} 9$ with $5 \mathrm{M} \mathrm{NaOH}$ to give a milky solution that was extracted three times with DCM. The combined organic layers were washed with brine, dried over $\mathrm{MgSO}_{4}$, filtered, and concentrated in vacuo to give a clear syrup (crude $N^{1}, N^{3}$-dibenzyl-2-deoxy-streptamine) that was used without further purification.

A round-bottom flask containing the dried, crude syrup obtained in the previous step was charged with anhydrous THF (200 mL) and cooled to 0 C. Carbonyldiimidazole (18.0 g, $98.5 \mathrm{mmol})$ was added all at once, and the mixture was allowed to stir overnight after slowly warming to room temperature. After the addition of $100 \mathrm{~mL}$ of $1 \mathrm{M} \mathrm{NaOH}$, the reaction mixture was stirred at room temperature for an additional hour. The solution was then concentrated in vacuo to yield 
a residue that was partitioned between EtOAc and saturated $\mathrm{NH}_{4} \mathrm{Cl}$. The organic layer was separated, washed with brine, dried over $\mathrm{MgSO}_{4}$, filtered, and concentrated in vacuo. The resulting residue was triturated with $\mathrm{MeOH}$ to precipitate compound 21 (46\% yield over three steps) as a white powder. ${ }^{1} \mathrm{H}$ NMR (DMSO, $\left.400 \mathrm{MHz}\right) \delta(\mathrm{ppm}) 7.35-7.22(\mathrm{~m}, 10 \mathrm{H}), 6.04$ (d, $J=5.0$ $\mathrm{Hz}, 1 \mathrm{H}, \mathrm{OH}), 4.34-4.12(\mathrm{ABq}, J=14.9 \mathrm{~Hz}, 4 \mathrm{H}, \mathrm{PhCH} 2), 4.06(\mathrm{dd}, J=9.3,5.0 \mathrm{~Hz}, 1 \mathrm{H}, \mathrm{H} 5), 3.85(\mathrm{~m}$, $2 \mathrm{H}, \mathrm{H} 4 / \mathrm{H} 6), 3.06$ (td, $J=11.6,3.3 \mathrm{~Hz}, 2 \mathrm{H}, \mathrm{H} 1 / \mathrm{H} 3$ ), 2.21 (dt, $J=10.9,3.4 \mathrm{~Hz}, 1 \mathrm{H}, \mathrm{H} 2 \mathrm{eq}$ ), 1.38 (q, $J=$ $\left.11.3 \mathrm{~Hz}, 1 \mathrm{H}, \mathrm{H} 2_{\mathrm{ax}}\right) .{ }^{13} \mathrm{C}$ NMR (DMSO, $101 \mathrm{MHz}$ ) $\delta$ (ppm) 159.3, 159.2, 136.7, 129.0, 128.5, 128.1, 83.8, 69.1, 57.7, 49.1, 46.4. HRMS (ESI) calcd. for $\mathrm{C}_{22} \mathrm{H}_{22} \mathrm{~N}_{2} \mathrm{O}_{5}[\mathrm{M}+\mathrm{H}]^{+}=395.1607$, found: 395.1619 .

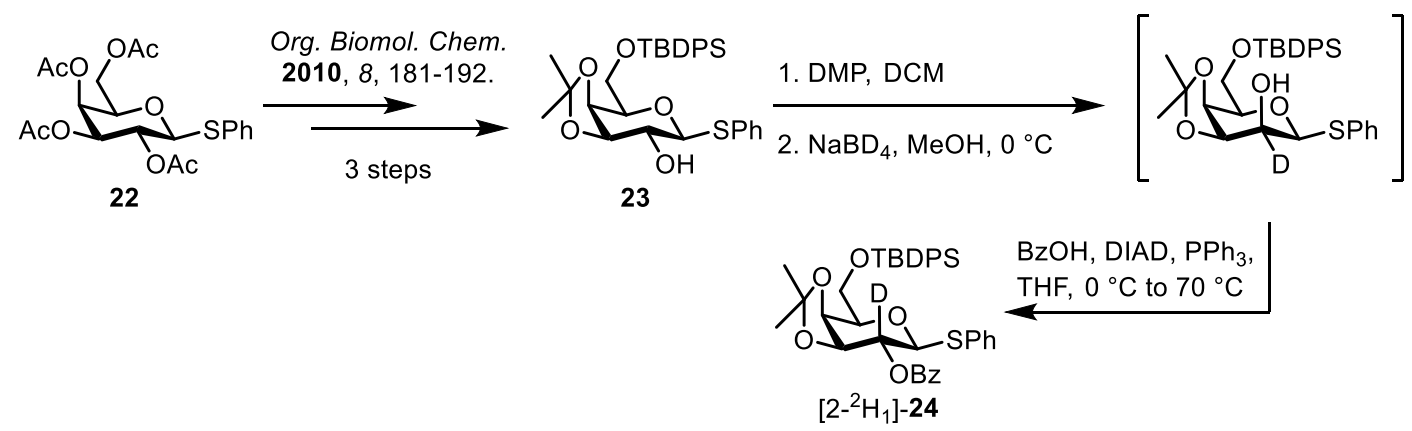

Glycosyl Donor: Phenyl 2-O-benzoyl-6-O-(tert-butyldiphenylsilyl)-2-deuterio-3,4-O-isopropylidene-1-thio- $\beta$-D-galactopyranoside $\left(\left[2-{ }^{2} \mathrm{H}_{1}\right]-24\right)$

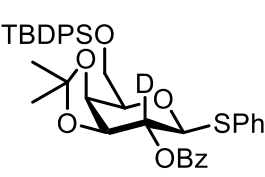

To a round-bottom flask containing alcohol $23^{4}$ (2.38 g, $\left.4.32 \mathrm{mmol}\right)$ dissolved in DCM (43.2 $\mathrm{mL})$ was added Dess-Martin periodinane $(3.67 \mathrm{~g}, 8.64 \mathrm{mmol})$ at room temperature. The reaction was stirred for $4 \mathrm{~h}$ and subsequently diluted with DCM. The organic layer was washed three times with a 1:1 solution of saturated $\mathrm{NaHCO}_{3}$ and $10 \% \mathrm{Na}_{2} \mathrm{~S}_{2} \mathrm{O}_{3}$. After another wash with brine, the organic layer was dried over $\mathrm{Na}_{2} \mathrm{SO}_{4}$, filtered, and concentrated in vacuo give the crude ketone which was used without further purification.

The crude ketone was dissolved in $50 \mathrm{~mL} \mathrm{MeOH}$. Sodium borodeuteride (271 mg, $6.48 \mathrm{mmol}$ ) was then added and the mixture was stirred for 45 min before neutralization with acetic acid. The solution was concentrated in vacuo, suspended in EtOAc, and washed with water, saturated $\mathrm{NaHCO}_{3}$, and brine. The organic layer was dried over $\mathrm{Na}_{2} \mathrm{SO}_{4}$, filtered, and concentrated in vacuo to give the crude alcohol product which was used without further purification. 
Benzoic acid (633 mg, $5.18 \mathrm{mmol})$ and triphenylphosphine $(1.36 \mathrm{~g}, 5.18 \mathrm{mmol})$ were added to a flame-dried round-bottom flask containing the crude reduction product dissolved in anhydrous THF (17.2 mL). DIAD (1.02 mL, $2.85 \mathrm{mmol})$ was then added, and the solution was allowed to stir at room temperature until consumption of alcohol was observed by TLC (ca. $12 \mathrm{~h}$ ). The solution was then diluted with EtOAc and washed sequentially with saturated $\mathrm{NH}_{4} \mathrm{Cl}$ and brine. The organic layer was dried over $\mathrm{Na}_{2} \mathrm{SO}_{4}$, filtered, and concentrated in vacuo. The resulting residue was purified by flash chromatography (9:1 hexanes/EtOAc) to give compound $\left[\mathbf{2 -}{ }^{\mathbf{2}} \mathbf{H}_{\mathbf{1}}\right]-\mathbf{2 4}$ (70\% yield) as a white solid. ${ }^{1} \mathrm{H} N M R\left(\mathrm{CDCl}_{3}, 400 \mathrm{MHz}\right) \delta(\mathrm{ppm}) 8.07(\mathrm{dd}, J=8.3,1.4 \mathrm{~Hz}, 2 \mathrm{H}), 7.74-$ $7.71(\mathrm{~m}, 4 \mathrm{H}), 7.58(\mathrm{~m}, 1 \mathrm{H}), 7.48-7.37(\mathrm{~m}, 10 \mathrm{H}), 7.24-7.20(\mathrm{~m}, 3 \mathrm{H}), 4.79(\mathrm{~s}, 1 \mathrm{H}, \mathrm{H}-1), 4.36(\mathrm{~s}, 2 \mathrm{H}$, $\mathrm{H}-3, \mathrm{H}-4), 4.08-3.96(\mathrm{~m}, 3 \mathrm{H}, \mathrm{H}-5, \mathrm{H}-6, \mathrm{H}-6), 1.57$ (s, 3H), 1.34 (s, 3H), $1.08(\mathrm{~s}, 9 \mathrm{H}) .{ }^{13} \mathrm{C} \mathrm{NMR}\left(\mathrm{CDCl}_{3}\right)$, $101 \mathrm{MHz}) \delta$ (ppm) 165.39, 135.66, 135.64, 133.77, 133.29, 133.27, 133.15, 131.78, 129.92, 129.87, 129.76, 128.86, 128.35, 127.74, 127.69, 127.54, 110.55, 86.09, 77.29, 77.08, 73.48, 62.97, 27.71, 26.80, 26.35, 19.23. HRMS (ESI) calcd. for $\mathrm{C}_{38} \mathrm{H}_{41} \mathrm{DO}_{6} \mathrm{SSi}\left[\mathrm{M}+\mathrm{NH}_{4}\right]^{+}=673.2878$, found: 673.2911 .

\section{S2.10. Synthesis of Pseudodisaccharides}
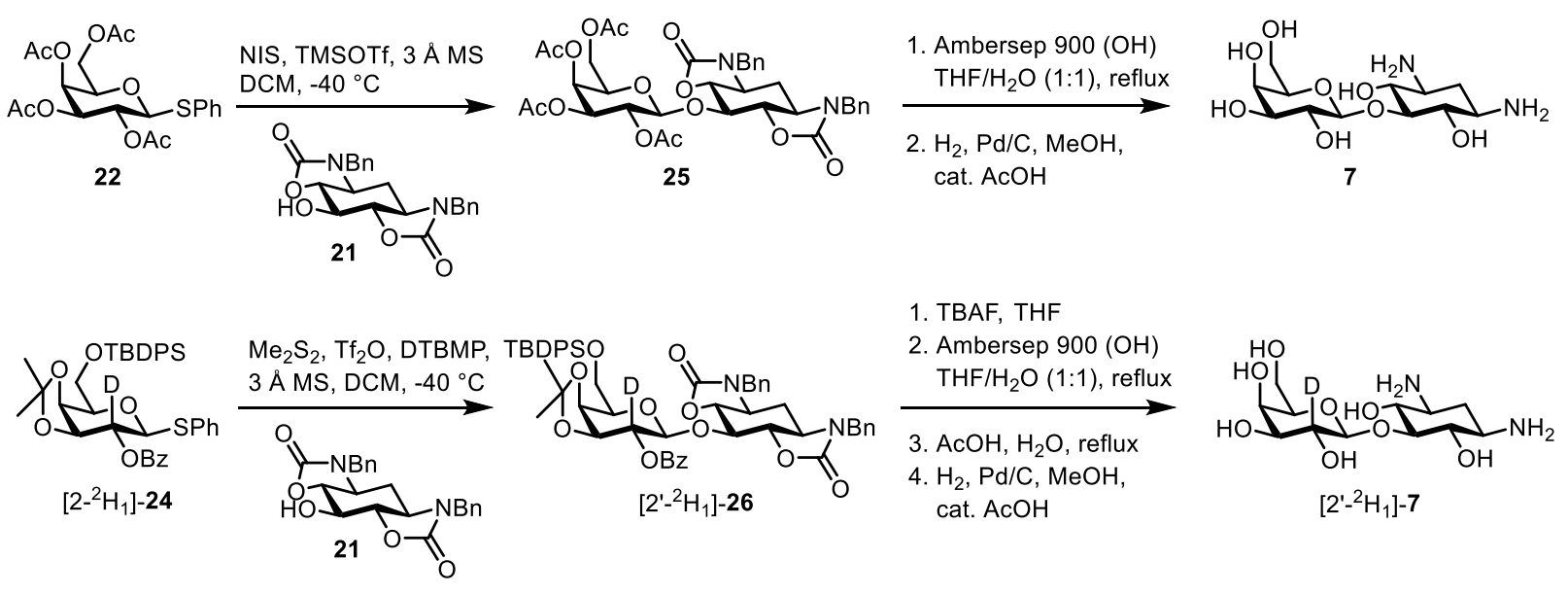

Glycosylation procedure A. A flame-dried round-bottom flask containing $3 \AA$ molecular sieves (MS) was charged with thioglycoside donor (22, 1.2 eq.), 21 (1.0 eq.), $N$-iodosuccinimide (1.5 eq.), and anhydrous DCM (0.1 M). The mixture was cooled to $-40 \mathrm{C}$, and TMSOTf (1.5 eq.) was added dropwise. The mixture was stirred and slowly warmed to room temperature over the course of $12 \mathrm{~h}$. The reaction mixture was quenched by the addition of solid $\mathrm{NaHCO}_{3}, \mathrm{Na}_{2} \mathrm{~S}_{2} \mathrm{O}_{3}$, and enough 
water to initiate a color change of the solution from deep red to golden yellow. The mixture was filtered, dried over $\mathrm{Na}_{2} \mathrm{SO}_{4}$, and concentrated in vacuo. The resulting residue was triturated with $\mathrm{MeOH}$ to precipitate the protected pseudodisaccharide.

Glycosylation procedure B. ${ }^{5}$ Freshly prepared $1 \mathrm{M} \mathrm{Me}_{2} \mathrm{~S}_{2}-\mathrm{Tf}_{2} \mathrm{O}$ reagent ${ }^{5}$ in dry DCM (1.8 eq.) was added at $-40 \mathrm{C}$ to a flame-dried round-bottom flask containing $3 \AA$ MS, thioglycoside donor (24, 1.2 eq.), 21 (1 eq.), 2,6-di-tert-butyl-4-methylpyridine (DTBMP, 1.2 eq.), and anhydrous DCM (0.5 M). The reaction mixture was stirred and slowly warmed to room temperature over the course of $12 \mathrm{~h}$. The reaction mixture was quenched by the addition of excess triethylamine and diluted with DCM. After filtration, the organic layer was washed with $1 \mathrm{M} \mathrm{HCl}$, saturated $\mathrm{NaHCO}_{3}$, and brine, dried over $\mathrm{Na}_{2} \mathrm{SO}_{4}$, and concentrated in vacuo. The resulting residue was triturated with $\mathrm{MeOH}$ to precipitate the protected pseudodisaccharide.

\section{$N^{1}, N^{3}$-Dibenzyl- $N^{1}, O^{6} ; N^{3}, O^{4}$-dicarbonyl-5-O-[2,3,4,6-tetra-O-acetyl- $\beta$-D-galactopyranosyl]-2- deoxy-streptamine (25)}

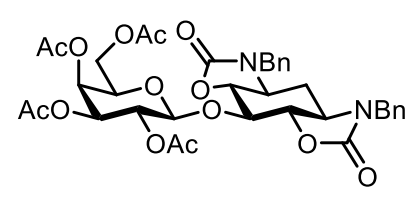

Obtained as a white powder (62\% yield) via procedure A using $\mathbf{2 1}$ and phenyl 2,3,4,6-tetra-O-acetyl- $\beta$-D-thiogalactopyranoside (22). ${ }^{6}{ }^{1} \mathrm{H} \mathrm{NMR}$ (DMSO, $400 \mathrm{MHz}) \delta$ (ppm) 7.35-7.22 (m, 10H, Ar), 5.26-5.21 (m, 2H, H$\left.2^{\prime}, H_{-3}{ }^{\prime}\right), 4.92\left(\mathrm{dd}, J=10.0,7.9 \mathrm{~Hz}, 1 \mathrm{H}, \mathrm{H}-4^{\prime}\right), 4.83\left(\mathrm{~d}, J=8.0 \mathrm{~Hz}, 1 \mathrm{H}, \mathrm{H}-1^{\prime}\right), 4.47(\mathrm{t}, J=9.3 \mathrm{~Hz}, 1 \mathrm{H}$, $\mathrm{H}-5), 4.29\left(\mathrm{ABq}, J=15.5 \mathrm{~Hz}, 4 \mathrm{H}, 2 \times \mathrm{ArCH}_{2}\right) 4.24-4.15\left(\mathrm{~m}, 1 \mathrm{H}, \mathrm{H}-5^{\prime}\right)$, 4.11-3.95 (m, 4H, H-6', H-6', $\mathrm{H}-4, \mathrm{H}-6), 3.26$ (td, J = 11.6, 3.4 Hz, 2H, H-1, H-3), 2.17 (dt, J = 10.7, $3.3 \mathrm{~Hz}, 1 \mathrm{H}, \mathrm{H}-2_{\text {eq }}$ ) , $2.11(\mathrm{~s}, 3 \mathrm{H}$ ), $2.01(\mathrm{~s}, 3 \mathrm{H}), 1.97(\mathrm{~s}, 3 \mathrm{H}), 1.90(\mathrm{~s}, 3 \mathrm{H}), 1.43$ (q, $J=11.4 \mathrm{~Hz}, 1 \mathrm{H}, \mathrm{H}-2 \mathrm{ax}) .{ }^{13} \mathrm{C}$ NMR (DMSO, $101 \mathrm{MHz}$ ) $\delta$ (ppm) 170.41, 170.36, 170.19, 170.03, 158.97, 158.87, 136.57, 128.98, 128.46, 128.08, 100.16 (C-1'), 80.82 (C-4), 79.26 (C-6), 75.74 (C-5), 70.47 (C-3'), 70.27 (C-5'), 69.10 (C-4') 67.54 (C-2'), 61.29 (C-6'), 58.16 (C-1, C-3), 47.03 ( $\left.\mathrm{PhCH}_{2}\right), 47.02\left(\mathrm{PhCH}_{2}\right), 25.94$ (C-2) 21.05, 20.86. HRMS (ESI) calcd. for $\mathrm{C}_{36} \mathrm{H}_{40} \mathrm{~N}_{2} \mathrm{O}_{14}[\mathrm{M}+\mathrm{H}]^{+}=725.2559$, found: 725.2571 .

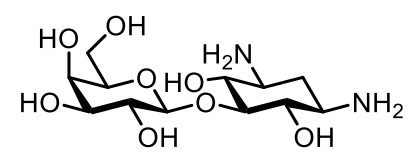

\section{5-O-( $\beta$-D-Galactopyranosyl)-2-deoxy-streptamine (7)}

Ambersep ${ }^{\circledast} 900(\mathrm{OH})$ and $\mathrm{H}_{2} \mathrm{O}(12.3 \mathrm{~mL})$ was added to a round-bottom flask containing 25 (89.4 mg, $0.123 \mathrm{mmol})$. The mixture was refluxed for $12 \mathrm{~h}$, cooled to room 
temperature, and then filtered. Additional water $(12.3 \mathrm{~mL})$ was used to rinse the resin. The filtrates were combined and concentrated in vacuo, and the crude, deacylated product was used without further purification.

$\mathrm{MeOH}(12.3 \mathrm{~mL}), 5 \%$ palladium on activated carbon $(35.2 \mathrm{mg})$, and a few drops of glacial acetic acid was added to a round-bottom flask containing the crude product obtained in the previous step. The reaction mixture was hydrogenated under one atmosphere of $\mathrm{H}_{2}$ at room temperature for $12 \mathrm{~h}$. The reaction mixture was then filtered through a Celite pad, concentrated in vacuo, and purified via silica gel flash chromatography (35\% conc. ammonia solution in $\mathrm{MeOH}$ ) to give compound 7 (58\% yield over two steps) as a white solid. ${ }^{1} \mathrm{H} N M R\left(D_{2} \mathrm{O}, 400 \mathrm{MHz}\right) \delta(\mathrm{ppm})$ $4.48\left(\mathrm{~d}, J=7.7 \mathrm{~Hz}, 1 \mathrm{H}, \mathrm{H}-1^{\prime}\right), 3.76\left(\mathrm{brd}, J=3.32 \mathrm{~Hz}, 1 \mathrm{H}, \mathrm{H}-4^{\prime}\right), 3.65-3.58\left(\mathrm{~m}, 2 \mathrm{H}, \mathrm{H}-6^{\prime}, \mathrm{H}-6^{\prime}\right)$, 3.56$3.54\left(\mathrm{~m}, 1 \mathrm{H}, \mathrm{H}-5^{\prime}\right), 3.53-3.51\left(\mathrm{~m}, 1 \mathrm{H}, \mathrm{H}-3^{\prime}\right), 3.45-3.43\left(\mathrm{~m}, 1 \mathrm{H}, \mathrm{H}-2^{\prime}\right), 3.42-3.40(\mathrm{~m}, 1 \mathrm{H}, \mathrm{H}-5), 3.25$ (t, J=9.49 Hz, 1H, H-4), 3.16 (t, J=9.46 Hz, 1H, H-6), 2.70 (ddd, J = 3.55 Hz, 11.3 Hz, 11.4 Hz, 2H, $\mathrm{H}-1, \mathrm{H}-3), 1.91$ (dt, J = $\left.11.3 \mathrm{~Hz}, 3.41 \mathrm{~Hz}, \mathrm{H}-2_{\text {eq }}\right), 1.15$ (q, J = 12.3 Hz, 1H, H-2 ax). ${ }^{13} \mathrm{C}$ NMR $\left(\mathrm{D}_{2} \mathrm{O}, 101\right.$ $\mathrm{MHz}) \delta(\mathrm{ppm}) 103.4$ (C-1'), 84.4 (C-5), 76.1 (C-4), 75.2 (C-5'), 74.9 (C-6), 72.5 (C-3'), 71.2 (C-2'), 68.5 (C-4'), 61.0 (C-6'), 50.2 (C-1, C-3), 33.9 (C-2). HRMS (ESI) calcd. for $\mathrm{C}_{12} \mathrm{H}_{24} \mathrm{~N}_{2} \mathrm{O}_{8}[\mathrm{M}+\mathrm{H}]^{+}=$ 325.1611, found: 325.1621.

\section{$N^{1}, N^{3}$-Dibenzyl- $N^{1}, O^{6} ; N^{3}, O^{4}$-dicarbonyl-5-O-[2-O-benzoyl-6-O-(tert-butyldiphenylsilyl)-2-}

\section{deuterio-3,4-O-isopropylidene- $\beta$-D-galactopyranosyl]-2-deoxy-streptamine $\left(\left[2{ }^{\prime}-{ }^{2} \mathrm{H}_{1}\right]-26\right)$}

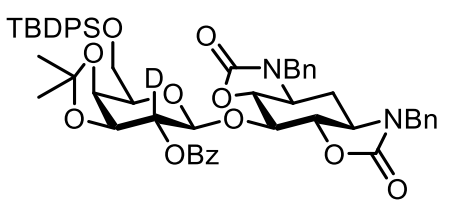

Obtained as a white powder (51\% yield) via procedure B using glycosyl acceptor 21 and glycosyl donor $\left[2-{ }^{2} \mathrm{H}_{1}\right]-24 .{ }^{1} \mathrm{H} \mathrm{NMR}\left(\mathrm{CDCl}_{3}\right.$, $400 \mathrm{MHz}) \delta(\mathrm{ppm})$ 8.14-8.05 (m, 2H), $7.70(\mathrm{dd}, J=7.5,1.9 \mathrm{~Hz}, 2 \mathrm{H})$, $7.64(\mathrm{dd}, J=8.0,1.6 \mathrm{~Hz}, 2 \mathrm{H}), 7.58-7.53(\mathrm{~m}, 1 \mathrm{H}), 7.45$ (dd, $J=8.3,7.0 \mathrm{~Hz}, 2 \mathrm{H}), 7.40$ (dt, $J=5.7,1.7$ $\mathrm{Hz}, 2 \mathrm{H}), 7.34-7.22(\mathrm{~m}, 9 \mathrm{H}), 7.17-7.13(\mathrm{~m}, 2 \mathrm{H}), 7.11(\mathrm{dd}, J=7.8,1.7 \mathrm{~Hz}, 2 \mathrm{H}), 4.83\left(\mathrm{~s}, 1 \mathrm{H}, \mathrm{H}-1^{\prime}\right), 4.31$ $(\mathrm{ABq}, J=15.0 \mathrm{~Hz}, 4 \mathrm{H}, 2 \mathrm{xhCH}), 4.33-4.24\left(\mathrm{~m}, 2 \mathrm{H}, \mathrm{H}-3^{\prime}, \mathrm{H}-4^{\prime}\right), 4.12(\mathrm{t}, J=9.4 \mathrm{~Hz}, 1 \mathrm{H}, \mathrm{H}-5), 4.10$ $\left(\mathrm{ABq}, J=15.0 \mathrm{~Hz}, \mathrm{PhCH}_{2}\right), 4.03-3.88\left(\mathrm{~m}, 3 \mathrm{H}, \mathrm{H}-5^{\prime}, \mathrm{H}-6^{\prime}, \mathrm{H}-6^{\prime}\right), 3.75$ (dd, J=11.7, 9.5 Hz, 1H, H-6), $3.64(\mathrm{dd}, J=11.8,9.3 \mathrm{~Hz}, 1 \mathrm{H}, \mathrm{H}-4), 2.77$ (td, $J=11.7,3.4 \mathrm{~Hz}, 1 \mathrm{H}, \mathrm{H}-1), 2.71$ (td, $J=11.6,3.4 \mathrm{~Hz}$, $1 \mathrm{H}, \mathrm{H}-3$ ), 1.82 (dt, J = 11.3, 3.4 Hz, 1H, H-2 eq) 1.59 (s, 3H), 1.32 (s, 3H), 1.13 (q, J = 11.5 Hz, 1H, H-

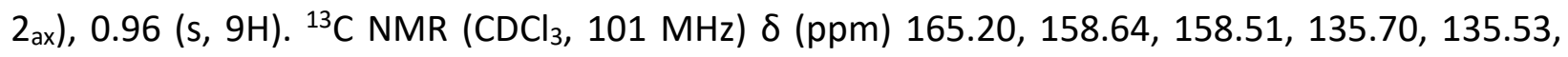


134.84, 134.72, 133.63, 133.03, 132.88, 129.94, 129.82, 129.59, 129.04, 128.90, 128.50, 128.39, 128.36, 128.31, 127.76, 127.72, 110.69 (C(OMe) $\left.)_{2)}\right), 98.78$ (C-1'), 82.11 (C-4), 78.98 (C-6), 77.30 $\left(\mathrm{C}-3^{\prime}\right), 74.13\left(\mathrm{C}-5^{\prime}\right), 73.44\left(\mathrm{C}-4^{\prime}\right), 72.37(\mathrm{C}-5), 62.91\left(\mathrm{C}-6^{\prime}\right), 57.80(\mathrm{C}-3), 57.68(\mathrm{C}-1), 47.69\left(\mathrm{PhCH}_{2}\right)$, $47.66\left(\mathrm{PhCH}_{2}\right), 27.68\left(\mathrm{CH}_{3}\right), 26.66\left(3 \mathrm{xCH}_{3}\right), 26.41(\mathrm{C}-2), 26.31\left(\mathrm{CH}_{3}\right), 19.20$ (C-Mes). HRMS (ESI) calcd. for $\mathrm{C}_{54} \mathrm{H}_{57} \mathrm{DN}_{2} \mathrm{O}_{11} \mathrm{Si}\left[\mathrm{M}+\mathrm{NH}_{4}\right]^{+}=957.4217$, found: 957.4206 .

\section{5-O-(2-Deuterio- $\beta$-D-galactopyranosyl)-2-deoxy-streptamine (7D)}

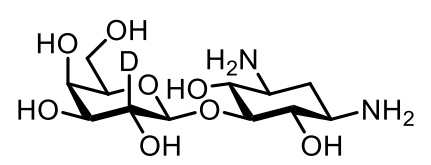

$\operatorname{TBAF}(1 \mathrm{M})$ in THF $(655 \mu \mathrm{L})$ was added to a round-bottom flask containing $\left[2^{\prime}-{ }^{2} \mathrm{H}_{1}\right]-24(308 \mathrm{mg}, 0.328 \mathrm{mmol})$ dissolved in THF $(1.82 \mathrm{~mL})$. The solution was stirred at room temperature until consumption of starting material was observed by TLC (ca. $6 \mathrm{~h}$ ). The solution was then concentrated in vacuo to give the crude, desilylated product that was used without further purification. Ambersep ${ }^{\circledR} 900$ $(\mathrm{OH})$ and $\mathrm{H}_{2} \mathrm{O}(32.7 \mathrm{~mL})$ was added to the same flask containing the crude compound, and the mixture was refluxed for $12 \mathrm{~h}$, cooled to room temperature, and then filtered. Additional water $(60 \mathrm{~mL})$ was used to rinse the resin. The filtrates were combined and concentrated in vacuo. The crude product was added to a round-bottom flask along with $35 \mathrm{~mL}$ of $\mathrm{AcOH}: \mathrm{H}_{2} \mathrm{O}(3: 2)$. The reaction mixture was refluxed for $12 \mathrm{~h}$, cooled to room temperature, and concentrated in vacuo to give crude $N^{1}, N^{3}$-dibenzyl-5-O-(2-deuterio- $\beta$-D-galactopyranosyl)-2-deoxy-streptamine that was used without further purification. $\mathrm{MeOH}(35 \mathrm{~mL}), 5 \%$ palladium on activated carbon (100 $\mathrm{mg}$ ), and a few drops of glacial acetic acid were added to the flask containing the crude product, and reaction mixture was hydrogenated under one atmosphere of $\mathrm{H}_{2}$ at room temperature for $12 \mathrm{~h}$. The reaction mixture was then filtered through a Celite pad, concentrated in vacuo, and purified via silica gel flash chromatography (35\% conc. ammonia solution in $\mathrm{MeOH}$ ) to give compound 7D (41\% yield over four steps) as a white solid. ${ }^{1} \mathrm{H} N \mathrm{NMR}\left(\mathrm{D}_{2} \mathrm{O}, 400 \mathrm{MHz}\right) \delta(\mathrm{ppm}) 4.49$ (s, 1H, H-1'), 3.77 (brd, J = 3.05 Hz, 1H, H-4'), 3.63-3.60 (m, 2H, H-6', H-6'), 3.58-3.54 (m, 1H, H$\left.5^{\prime}\right)$, 3.53-3.51 (m, 1H, H-3'), 3.41-3.39 (m, 1H, H-5), $3.21(\mathrm{t}, J=9.56 \mathrm{~Hz}, 1 \mathrm{H}, \mathrm{H}-4), 3.12(\mathrm{t}, J=9.53$ $\mathrm{Hz}, 1 \mathrm{H}, \mathrm{H}-6), 2.68-2.58(\mathrm{~m}, 2 \mathrm{H}, \mathrm{H}-1, \mathrm{H}-3), 1.92-1.82\left(\mathrm{~m}, 1 \mathrm{H}, \mathrm{H}-2_{\mathrm{eq}}\right), 1.08$ (q, J=12.0 Hz 1H, H-2ax). ${ }^{13} \mathrm{C}$ NMR (D $\left.{ }_{2} \mathrm{O}, 101 \mathrm{MHz}\right) \delta(\mathrm{ppm}) 103.4\left(\mathrm{C}-1^{\prime}\right), 84.6$ (C-5), 76.8 (C-4), 75.6 (C-6), 75.2 (C-5'), 72.5 
(C-3'), 70.8 (C-2', weak), 68.6 (C-4'), 61.0 (C-6'), 50.1 (C-1, C-3), 34.9 (C-2) HRMS (ESI) calcd. for $\mathrm{C}_{12} \mathrm{H}_{23} \mathrm{DN}_{2} \mathrm{O}_{8}[\mathrm{M}+\mathrm{H}]^{+}=326.1668$, found: 326.1672 .

\section{S2.11. Synthesis of Derivatized Pseudodisaccharide Standards}

Benzyl chloroformate (5.0 eq.) was added to a round-bottom flask containing the pseudodisaccharide (1.0 eq.) and solid $\mathrm{NaHCO}_{3}$ (7.0 eq.) dissolved in a 1:1 mixture of water and 1,4-dioxane $(0.1 \mathrm{M})$. The reaction mixture was stirred at room temperature for $12 \mathrm{~h}$ and then concentrated in vacuo to give a residue that was resuspended in a 1:1 mixture of pyridine and acetic anhydride $(0.1 \mathrm{M})$. The reaction mixture was stirred for $12 \mathrm{~h}$ at $35 \mathrm{C}$. Subsequent concentration of the solution in vacuo gave a residue that was purified by flash chromatography to give the derivatized pseudodisaccharide.

$O^{4}, O^{6}$-Diacetyl- $N^{1}, N^{3}$-dicarbobenzyloxy-5-O-[2,3,4,6-tetra-O-acetyl- $\beta$-D-galactopyranosyl]-2deoxy-streptamine (17)

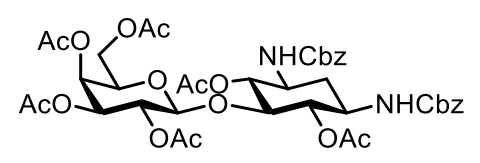

Obtained as a white solid (83\% yield over two steps, 60:40 EtOAc/Hexanes). ${ }^{1} \mathrm{H}$ NMR $\left(\mathrm{CDCl}_{3}, 400 \mathrm{MHz}\right) \delta(\mathrm{ppm}) 7.39-7.20(\mathrm{~m}$, $10 \mathrm{H}, \operatorname{Ar}), 6.51(\mathrm{~d}, J=9.4 \mathrm{~Hz}, 1 \mathrm{H}, \mathrm{NH}), 6.33(\mathrm{~d}, J=9.7 \mathrm{~Hz}, 1 \mathrm{H}, \mathrm{NH})$, $5.31\left(\mathrm{~s}, 1 \mathrm{H}, \mathrm{H}-4^{\prime}\right), 5.18-4.84\left(\mathrm{~m}, 7 \mathrm{H}, \mathrm{ArCH}_{2}, \mathrm{ArCH}_{2}, \mathrm{H}-2^{\prime}, \mathrm{H}-3^{\prime}, \mathrm{H}-5^{\prime}\right), 4.69(\mathrm{t}, \mathrm{J}=10.1 \mathrm{~Hz}, 1 \mathrm{H}, \mathrm{H}-5)$, $4.51\left(\mathrm{~d}, J=7.8 \mathrm{~Hz}, 1 \mathrm{H}, \mathrm{H}-1^{\prime}\right)$, 4.13-4.00 (m, 2H, H-6', H-6'), 3.91-3.71 (m, 4H, H-1, H-3, H-4, H-6), 2.26-2.18 (m, 1H, H-2 eq), $2.07(\mathrm{~s}, 3 \mathrm{H}), 2.05(\mathrm{~s}, 3 \mathrm{H}), 2.00(\mathrm{~s}, 3 \mathrm{H}), 1.92(\mathrm{~s}, 3 \mathrm{H}), 1.88(\mathrm{~s}, 6 \mathrm{H}), 1.61(\mathrm{q}$, $\left.J=13.0 \mathrm{~Hz}, 1 \mathrm{H} . \mathrm{H}-2_{\mathrm{ax}}\right) \cdot{ }^{13} \mathrm{C} \mathrm{NMR}\left(\mathrm{CDCl}_{3}, 101 \mathrm{MHz}\right) \delta$ (ppm) 171.46, 171.33, 170.43, 170.10, 170.04, 169.66, 156.24, 156.09, 136.76, 136.72, 128.41, 128.39, 127.98, 127.90, 127.72, 100.68, 77.72, 76.27, 73.00, 70.78, 70.60, 68.80, 66.95, 66.47, 61.07, 49.44, 49.05, 33.82, 20.82, 20.69, 20.63, 20.59, 20.55, 20.35. HRMS (ESI) calcd. for $\mathrm{C}_{40} \mathrm{H}_{48} \mathrm{~N}_{2} \mathrm{O}_{18}[\mathrm{M}+\mathrm{H}]^{+}=845.2981$, found: 845.3017.

$\mathrm{O}^{4}, \mathrm{O}^{6}$-Diacetyl- $N^{1}, N^{3}$-dicarbobenzyloxy-5-O-[2,3,4,6-tetra-O-acetyl-2-deuterio- $\beta$-Dgalactopyranosyl]-2-deoxy-streptamine (17D)

Obtained as a white solid $(78 \%$ yield over two steps, $60: 40$
EtOAc/Hexanes). ${ }^{1} \mathrm{H} \mathrm{NMR}\left(\mathrm{CDCl}_{3}, 400 \mathrm{MHz}\right) \delta(\mathrm{ppm})$ 7.38-7.20 (m, 
$10 \mathrm{H}, \mathrm{Ar}), 6.33(\mathrm{~d}, \mathrm{~J}=9.4 \mathrm{~Hz}, 1 \mathrm{H}, \mathrm{NH}), 6.15(\mathrm{~d}, J=9.6 \mathrm{~Hz}, 1 \mathrm{H} . \mathrm{NH}), 5.32\left(\mathrm{~d}, J=3.6 \mathrm{~Hz}, 1 \mathrm{H}, \mathrm{H}-4^{\prime}\right)$, 5.14-4.94 (m, 4H, 2x ArCH 2$), 4.91-4.82\left(\mathrm{~m}, 2 \mathrm{H}, \mathrm{H}-3^{\prime}, \mathrm{H}-5^{\prime}\right), 4.71(\mathrm{t}, J=10.1 \mathrm{~Hz}, 1 \mathrm{H}, \mathrm{H}-5), 4.52(\mathrm{~s}$, $\left.1 \mathrm{H}, \mathrm{H}-1^{\prime}\right), 4.08\left(\mathrm{~d}, J=6.6 \mathrm{~Hz}, 2 \mathrm{H}, \mathrm{H}-6^{\prime}, \mathrm{H}-6^{\prime}\right), 3.92-3.73(\mathrm{~m}, 4 \mathrm{H}, \mathrm{H}-1, \mathrm{H}-3, \mathrm{H}-4, \mathrm{H}-6), 2.25(\mathrm{dt}, J=$ 13.4, 4.4 Hz, 1H, H-2 eq), 2.08 (s, 3H), 2.07 (s, 3H), 2.00 (s, 3H), 1.93 (s, 3H), 1.90 (s, 3H), 1.90 (s, 3H), 1.59 (q, $\left.J=12.8 \mathrm{~Hz}, 2 \mathrm{H}, \mathrm{H}-2 \mathrm{ax}) .{ }^{13} \mathrm{C} \mathrm{NMR} \mathrm{(CDCl}, 101 \mathrm{MHz}\right) \delta$ (ppm) 171.31, 171.21, 170.45, 170.13 , 170.05, 169.80, 156.18, 156.04, 136.70, 136.66, 128.52, 128.44, 128.42, 128.02, 127.95, 127.77, 100.67, 77.72, 76.19, 73.01, 70.74, 70.61, 66.94, 66.54, 61.06, 49.49, 49.14, 33.91, 20.81, 20.70, 20.65, 20.60, 20.56, 20.36. HRMS (ESI) calcd. for $\mathrm{C}_{40} \mathrm{H}_{47} \mathrm{DN}_{2} \mathrm{O}_{18}[\mathrm{M}+\mathrm{H}]^{+}=846.3044$, found: 846.3023. 


\section{S3. Tables}

Table S1. Forward and reverse primers used for site-directed mutagenesis via Gibson assembly.

\begin{tabular}{|c|l|l|}
\hline Cysteine Mutants & \multicolumn{1}{|c|}{ Forward } & \multicolumn{1}{|c|}{ Reverse } \\
\hline C24A/C28A/C31A & $\begin{array}{l}\text { CTGAACGTCGCACACCACgCCAACCTCGGCgcCG } \\
\text { CGTCCgCCAGTCATCTGTCGCCGGTC }\end{array}$ & $\begin{array}{l}\text { GACCGGCGACAGATGACTggcGGACGCg } \\
\text { gcGCCGAGGTTggcGTGGTGTGCGACGTT } \\
\text { CAG }\end{array}$ \\
\hline C183A & $\begin{array}{l}\text { ATCGCCCATGTCTGGCGCgCtCACACGCTGTACG } \\
\text { AGGGC }\end{array}$ & $\begin{array}{l}\text { GCCCTCGTACAGCGTGTGagcGCGCCAG } \\
\text { ACATGGGCGAT }\end{array}$ \\
\hline
\end{tabular}

Table S2. NMR assignment of the derivatized HygY reaction product using galacamine substrate $\left(\mathrm{CDCl}_{3}, 500 \mathrm{MHz}\right)$.

\begin{tabular}{lll}
\hline Position & $\delta$ (multiplicity, $J$ in Hz) & $\delta c$ \\
\hline 1 & $3.79-3.85(\mathrm{~m})$ & 49.9 \\
$2 \mathrm{ax}$ & $1.30(\mathrm{q}, 12.6)$ & 34.6 \\
$2 \mathrm{eq}$ & $2.32(\mathrm{dt}, 4.26,13.0)$ & 1 \\
3 & $3.79-3.85(\mathrm{~m})$ & 49.9 \\
4 & $4.74(\mathrm{t}, 10.45)$ & 75.1 \\
5 & $3.86-3.92(\mathrm{~m})$ & 78.5 \\
6 & $4.74(\mathrm{t}, 10.45)$ & 73.4 \\
$1^{\prime}$ & $4.65(\mathrm{~s})$ & 99.1 \\
$2^{\prime}$ & $5.2(\mathrm{~d}, 3.64)$ & 66.6 \\
$3^{\prime}$ & $4.97(\mathrm{t}, 3.69)$ & 67.9 \\
$4^{\prime}$ & $5.24(\mathrm{~s})$ & 64.7 \\
$5^{\prime}$ & $3.88-3.83(\mathrm{~m})$ & 71.4 \\
$6^{\prime}$ & $4.11(\mathrm{~d}, 6.55)$ & 61.3 \\
$-\mathrm{Ac}\left(\mathrm{CH}_{3}\right)$ & $1.96,1.97,1.99,2.05,2.09,2.10(\mathrm{~s})$ & $20.3-20.7$ \\
$-\mathrm{Ac}(\mathrm{C}=\mathrm{O})$ & & $169.6,169.9,170.5,170.8$ \\
$-\mathrm{Cbz}\left(\mathrm{CH}_{2}\right)$ & $5.02-5.5 .14(\mathrm{~m})$ & 66.9 \\
$-\mathrm{Cbz}(\mathrm{Ar})$ & $7.30-7.40(\mathrm{~m})$ & $128.0-128.6$ \\
$-\mathrm{Cbz}(\mathrm{C}=\mathrm{O})$ & & 155.8
\end{tabular}




\section{S4. Supporting Figures}

A

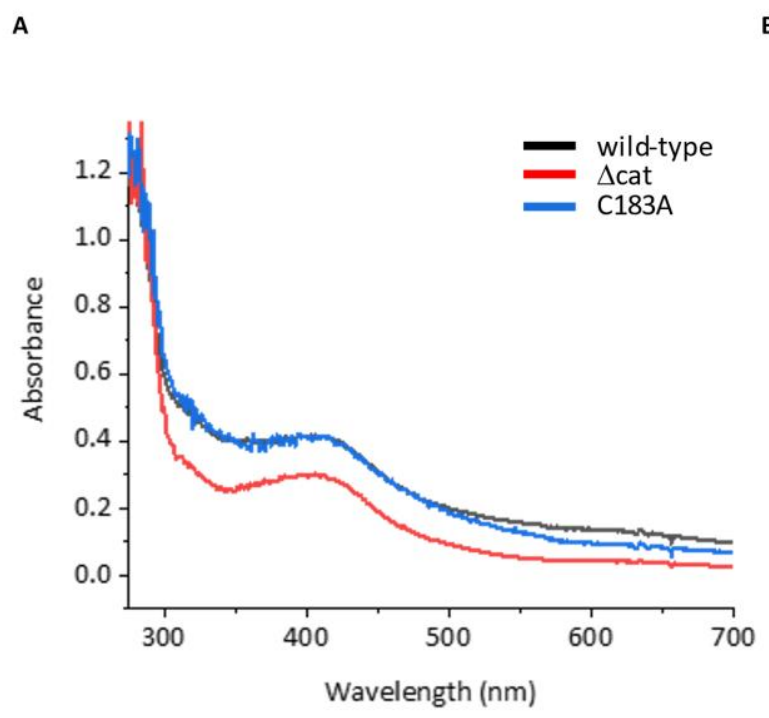

B

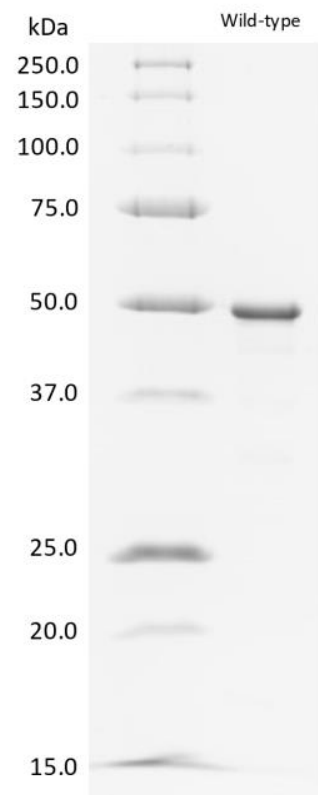

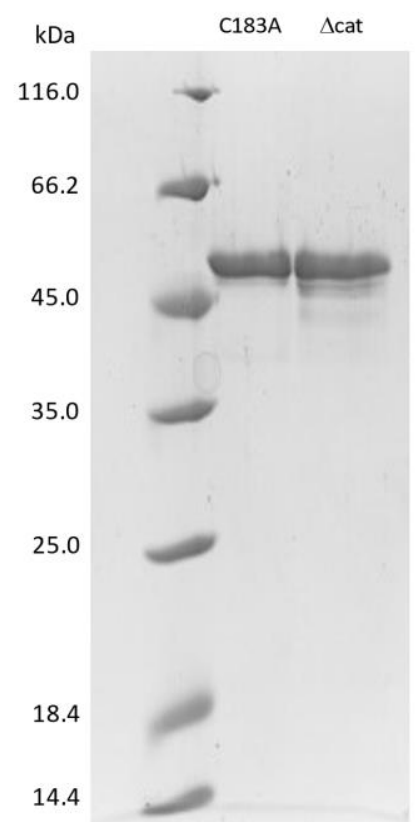

Figure S1. (A) UV/Vis spectra of the isolated HygY wild-type and variants following reconstitution. (B) SDS-PAGE gel of the respective proteins in (A). 
CLUSTAL O(1.2.4) multiple sequence alignment

$\begin{array}{ll}1 & \text { NeoN } \\ 2 & \text { HygY }\end{array}$

2 HygY

consensus/908

1 NeoN

2 HygY

3 BtrN

Consensus/908

1[ $----M T T D I V W P P P V R Q V R A Y R N I V V D G A C$
MSYGLVDGKVVSP------EGCELNVAHHC
$------M D K L F-------$ SMIEVEVNSQC
......shlh...... thhpl.VsttC

ITIYPKIVDHLQKRA--AEGYRVEVLSNTGTKI PRALEGRPDLLWVF---------SVDGHTEAMNAKRGLKQPQIDRILD

PLLHPELVPLLNLVRD SGIAPHTTVCTNGLILPRMRD----DFWAAVDEVEISVYPDRE--IPEEKMA GVRA-------PLICKNLDLFVGMTSEYI PRARP I YTNGDFLTEKRL----QT---LTELGIQKF IVTQHAGAKHKFRGV---------

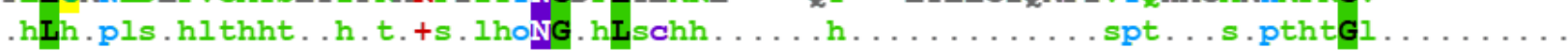

161

$1 \mathrm{NeON}$

2 HygY

3 BtrN

consensus/908

$1 \mathrm{NeON}$

2 HygY

3 BtrN

consensus/908

AAVELGA-ELQTVYWGQPVEEVNAYIDLLESRGYRGLLHFMPLLAFKGRPLTVNLRYQDLHPADFLAPPEYFRRWNHIFE YADKHGV-RLTLAYYSHFR-----YSYAERGTGDD GLVRH----IYDTCQIAHVWRCHTLYEGHFFKCPOSV------FI YDQLA GADKEKVVYLDHSD-----LILSNRGGILDNI PQASK--ANMSCMVPSNLAVV-TVLGNVLPCFEDF------NQ hs..hGs.c.phsyhsp......h....cuth.csl.ph...h..sp.ls.shth..hh.uphh.s.p.h.....

$$
\begin{aligned}
& \text { H-atom donor } \\
& +\quad+. \quad \text { auxiliary cluster }
\end{aligned}
$$

241

. auxiliary cluster . ++

TGRRDAVCDQITNGYNYQVSGDEIRMVKCDCYSVPKHLVHGFGPIREFDDWPCGTCIANOEFNNSR-----ERMRVPOGR PQVLEGAGD PMAD GL---------RL--SDAPDF PERLLAYLRS PEP--LRACRNCLGSAGMRMPHQQRNRRNFRELQDH KMVMGNISEHHISDI--------WNN--DKFTSFRKMIKE--GHRGK--SDICKNCNNVSV-

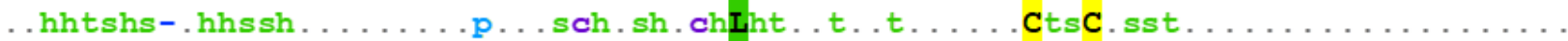

321

$\begin{array}{ll}1 & \text { NeoN } \\ 2 & \text { HygY } \\ 3 & \text { BtrN } \\ & \text { Consensus/908 }\end{array}$

TTEELTDRQYLRLIDERPNADDGCAVGDRDAWRERLAEQPPAAVAASGHTGADRPAESDESGRRAQSARYAQGKRF

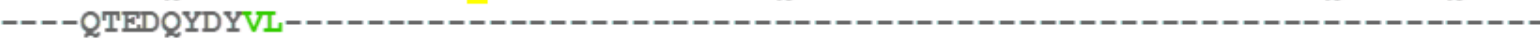

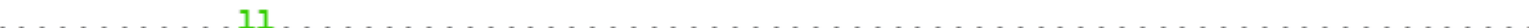

Figure S2. Sequence alignment of HygY with related radical SAM enzymes NeoN (epimerase) and BtrN (dehydrogenase) using the MView tool from EMBL-EBI. ${ }^{7}$ Commonalities between HygY and these enzymes include internal positioning of the cysteine $\mathrm{H}$-atom donor within the Twitch domain (NeoN) and good alignment with the Twitch domain of BtrN. 


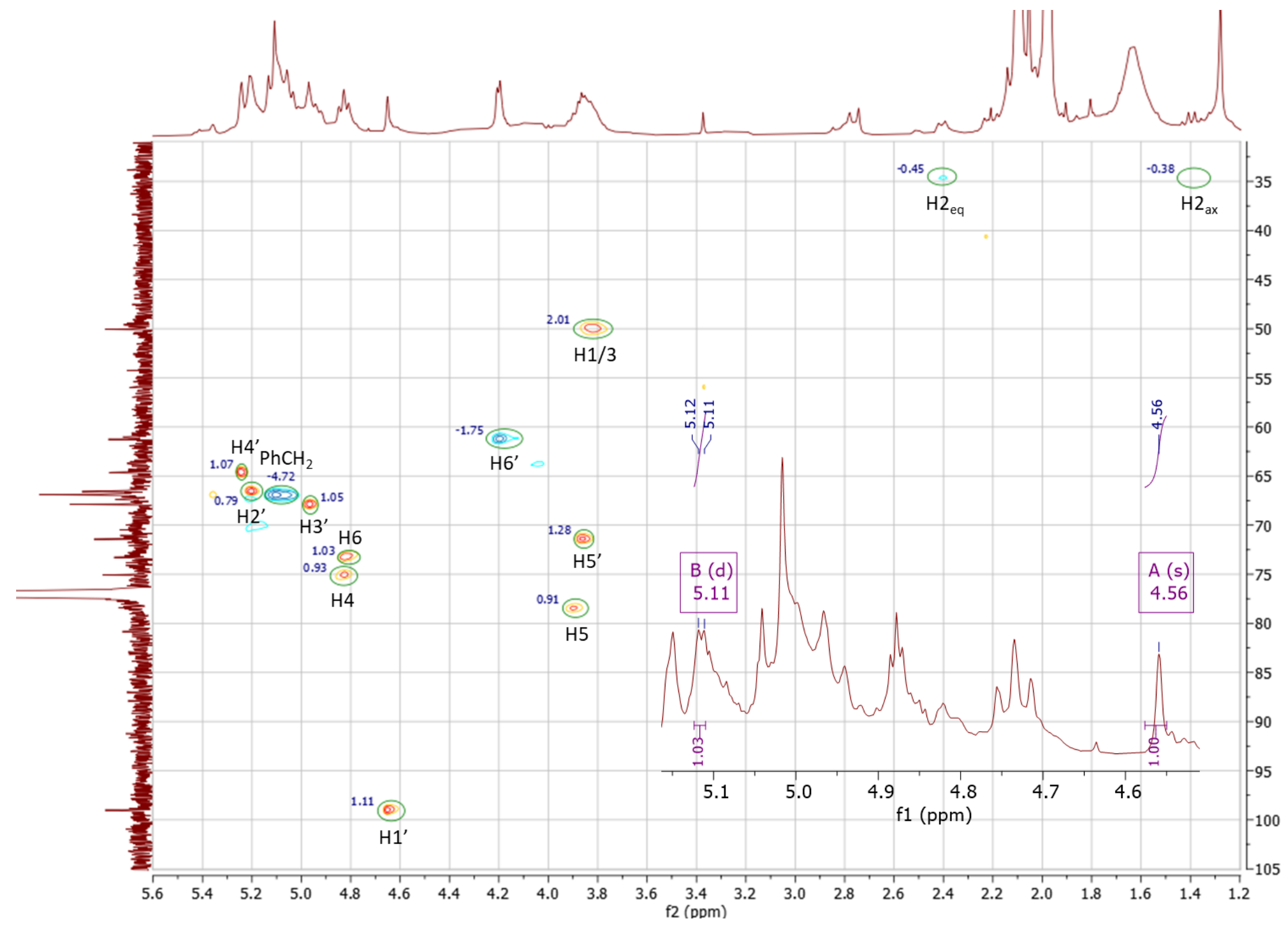

흥

Figure S3. HSQC spectrum (zoom, ring region) of isolated $\mathbf{1 8}$ from HygY. 


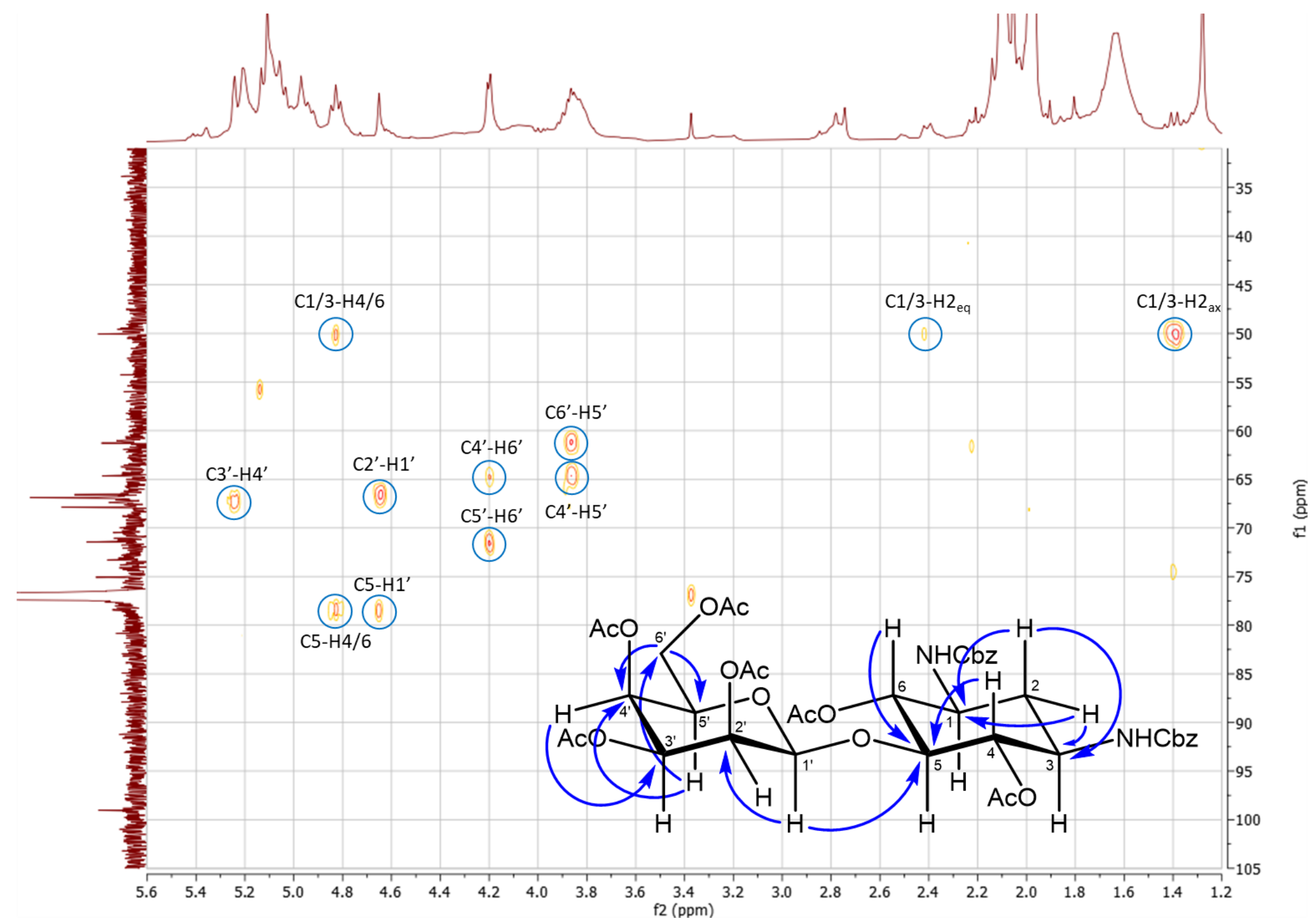

Figure S4. HMBC spectrum (zoom, ring region) of isolated 18 from HygY. 

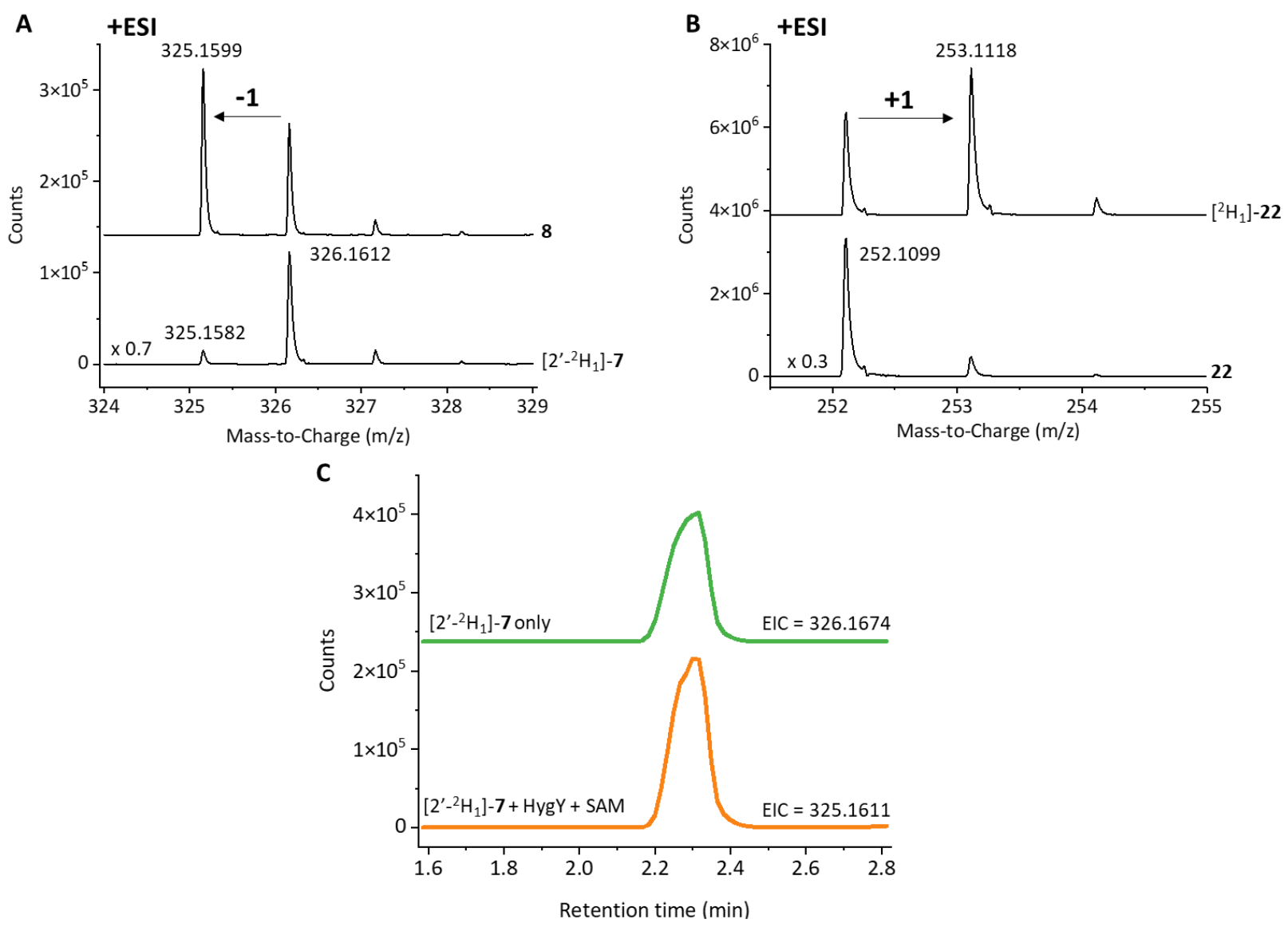

Figure S5. Additional LC-MS traces for the HygY-catalyzed conversion of 7D to C-2' epimer 8. (A, upper trace) MS analysis of the epimer (8) generated from substrate 7D in $\mathrm{H}_{2} \mathrm{O}$ showing loss of the deuterium; ( $A$, lower trace) MS of $\mathbf{7}$ for comparison. ( $B$, upper trace) MS analysis of deuterated 5'-dAdo (22), which received the deuteron from 7D; (B, lower trace) MS of 5'-dAdo for comparison. (C, upper trace) EIC of the synthetic standard 7D; (C, lower trace) EIC of the epimer (8) generated from 7D in $\mathrm{H}_{2} \mathrm{O}$ highlighting the overlapping retention times. 


\section{S6. References}

1. Sato, S.; Kudo, F.; Kim, S.-Y.; Kuzuyama, T.; Eguchi, T. Methylcobalamin-dependent radical SAM C-methyltransferase Fom3 recognizes cytidylyl-2-hydroxyethylphosphonate and catalyzes the nonstereoselective $C$-methylation in fosfomycin biosynthesis. Biochemistry 2017, 56, 3519-3522.

2. Stoll, S; Schweiger, A. An adaptive method for computing resonance fields for continuouswave EPR spectra. Chem. Phys. Lett. 2003, 380 (3-4), 464-470.

3. Moreno-Vargas, A.; Gerber-Lemaire, S.; Coste, G.; Horlacher, T.; Molina, L.; Carmona, A.; Robina, I.; Seeberger, P. Synthesis and biological evaluation of modified 2-deoxystreptamine dimers. Synthesis 2011, 2011 (11), 1759-1770.

4. Tam, P. H.; Lowary, T. L. Epimeric and amino disaccharide analogs as probes of an $\alpha-(1 \rightarrow 6)-$ mannosyltransferase involved in mycobacterial lipoarabinomannan miosynthesis. Org. Biomol. Chem. 2010, 8 (1), 181-192.

5. Tatai, J.; Fügedi, P. A new, powerful glycosylation method: activation of thioglycosides with dimethyl disulfide-triflic anhydride. Org. Lett. 2007, 9 (22), 4647-4650.

6. Balcerzak, A. K.; Ferreira, S. S.; Trant, J. F.; Ben, R. N. Structurally diverse disaccharide analogs of antifreeze glycoproteins and their ability to inhibit ice recrystallization. Bioorg Med. Chem. Lett. 2012, 22 (4), 1719-1721.

7. Madeira, F.; Park, Y. mi; Lee, J.; Buso, N.; Gur, T.; Madhusoodanan, N.; Basutkar, P.; Tivey, A. R. N.; Potter, S. C.; Finn, R. D.; Lopez, R. The EMBL-EBI search and sequence analysis tools APIs in 2019. Nucleic Acids Research 2019, 47 (W1), W636-W641. 
S7. Appendix: NMR Spectra 


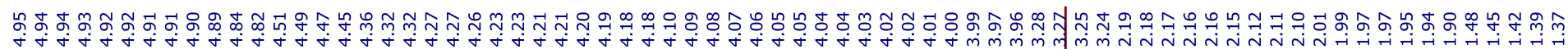

(n)
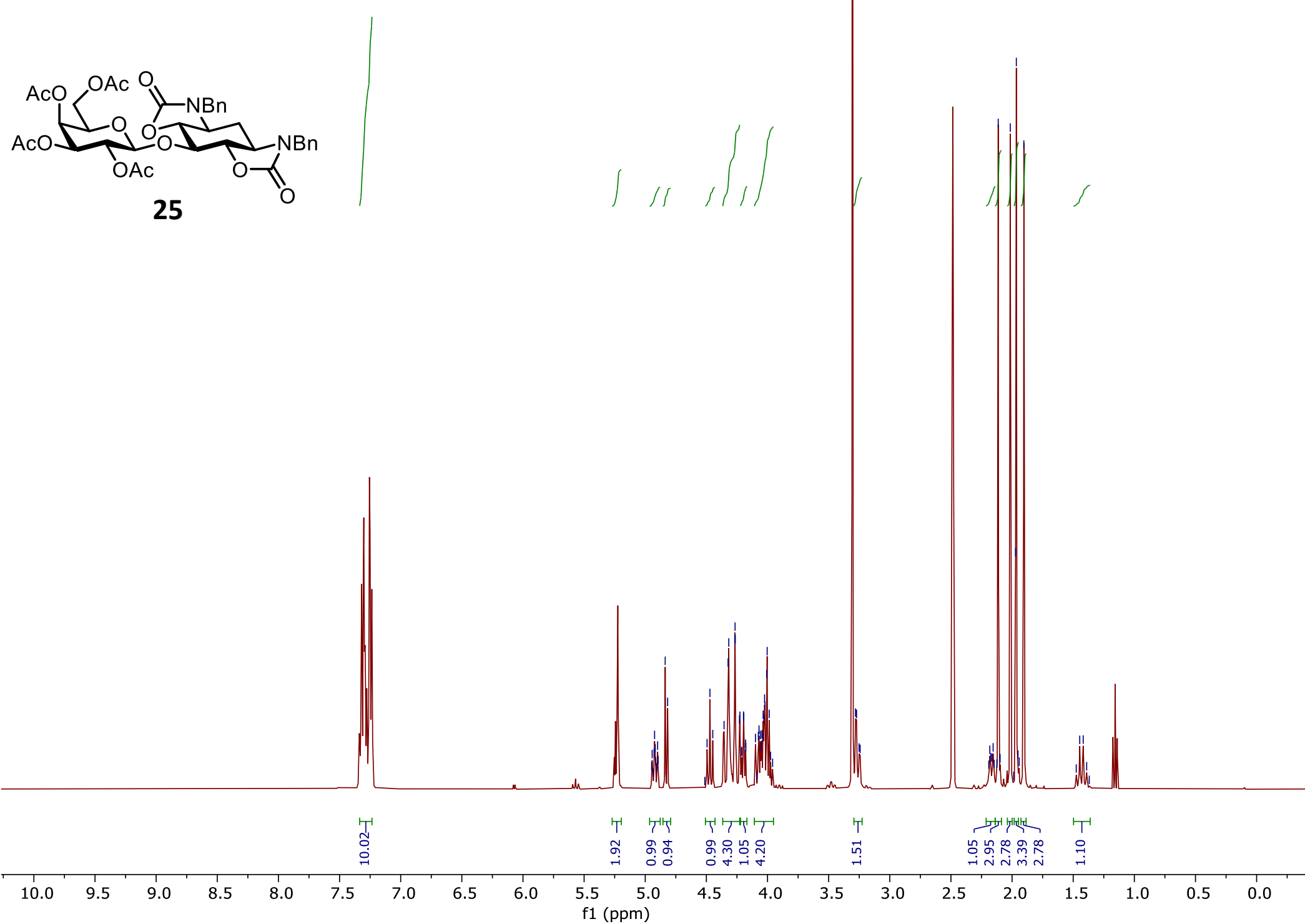


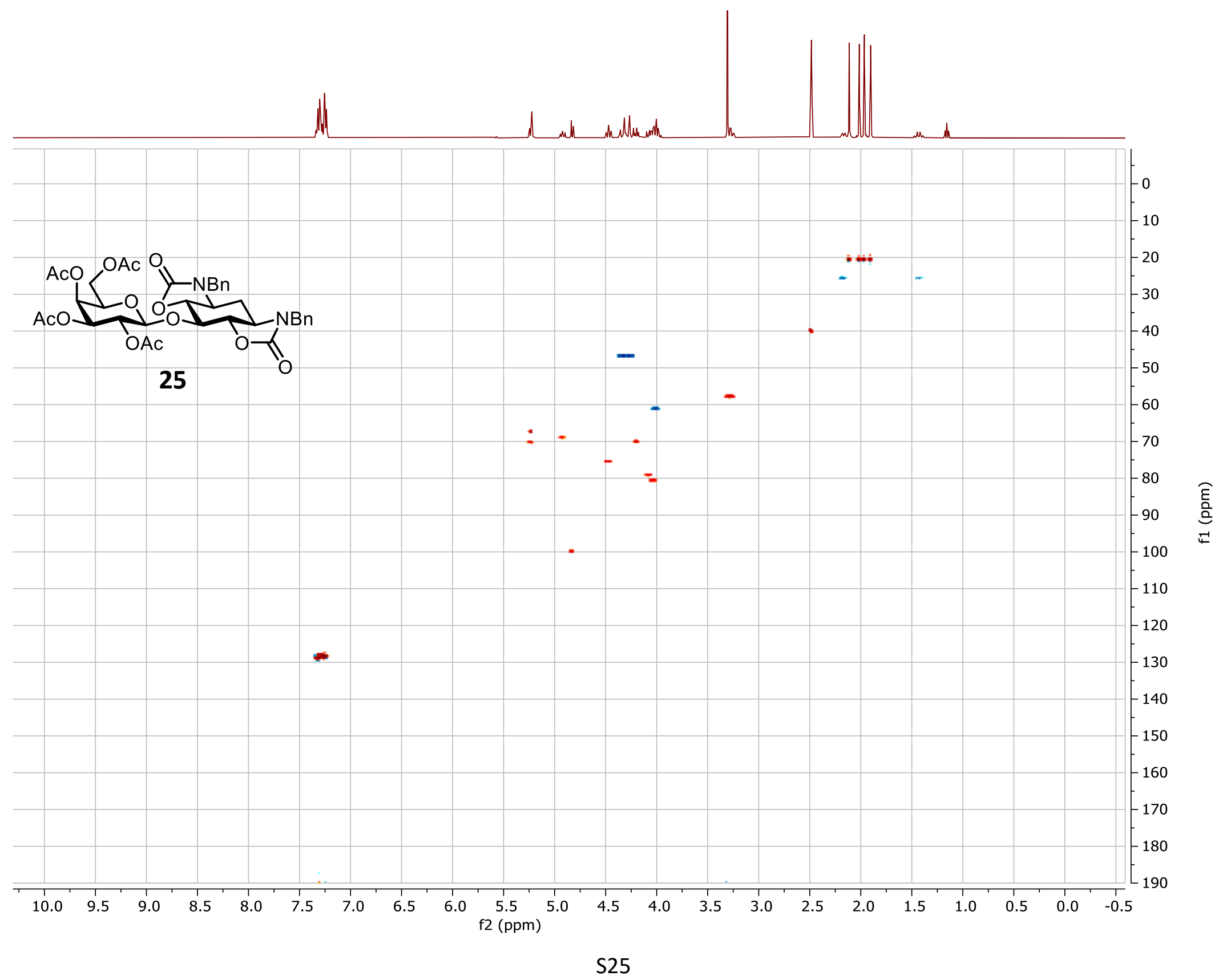




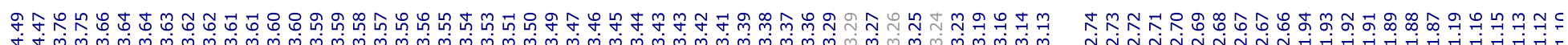

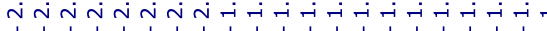

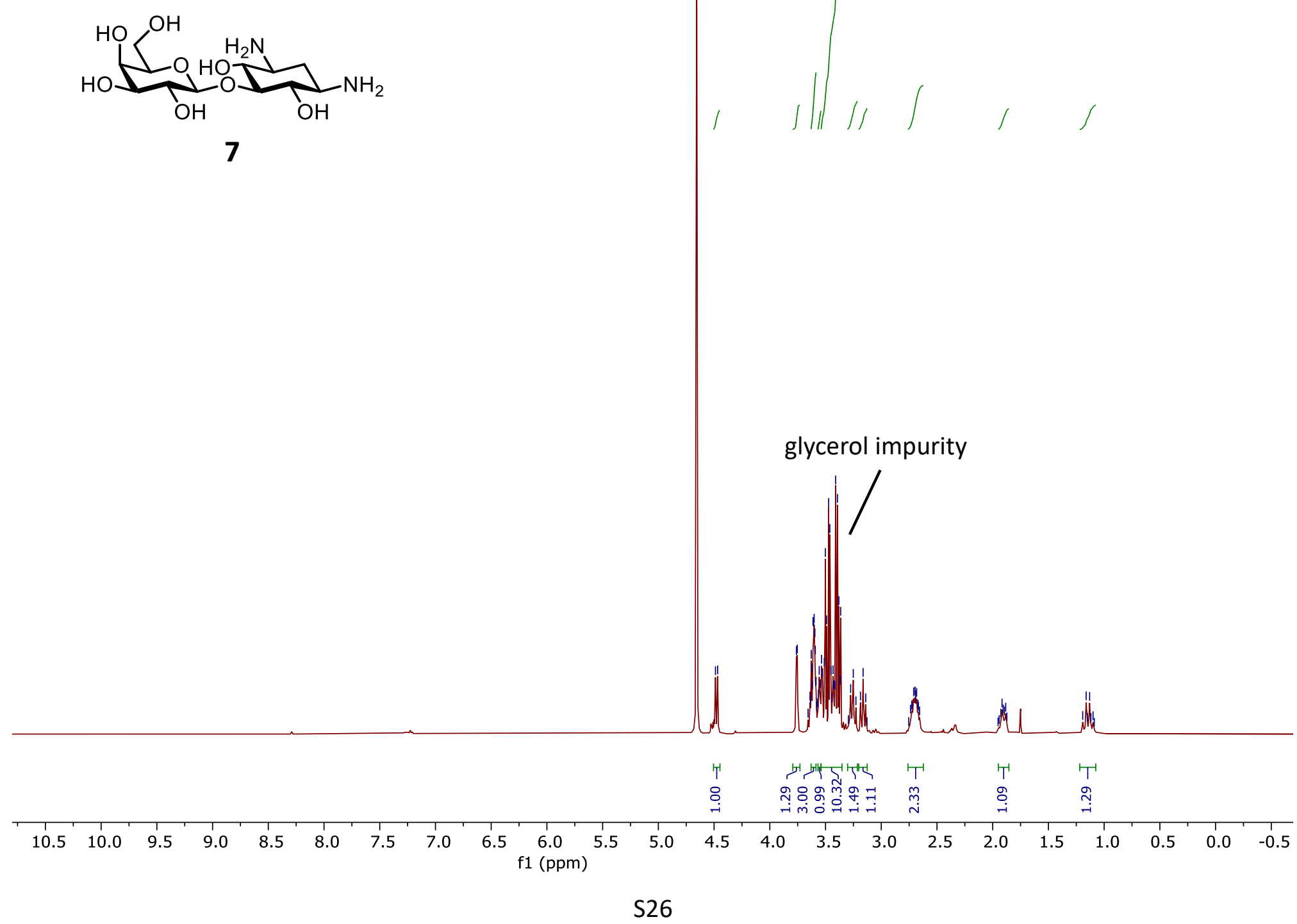




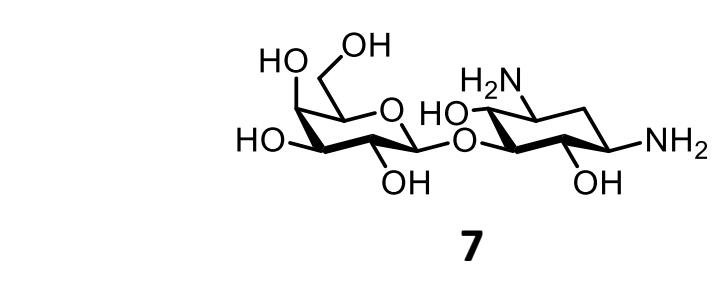

| l|

glycerol impurity

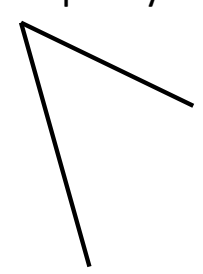

$\begin{array}{llllll}150 & 140 & 130 & 120 & 110 & 100\end{array}$ f1 (ppm) 


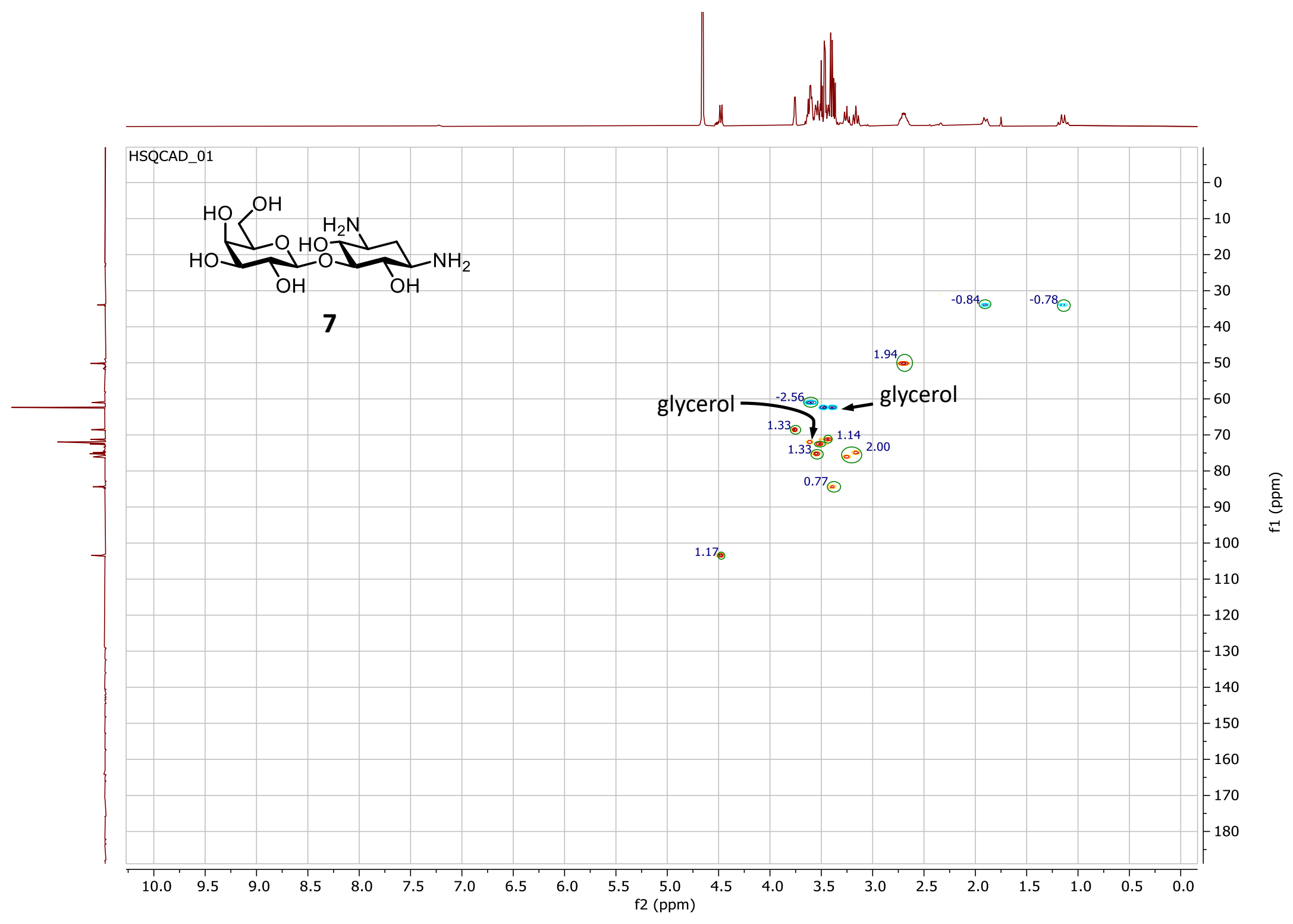




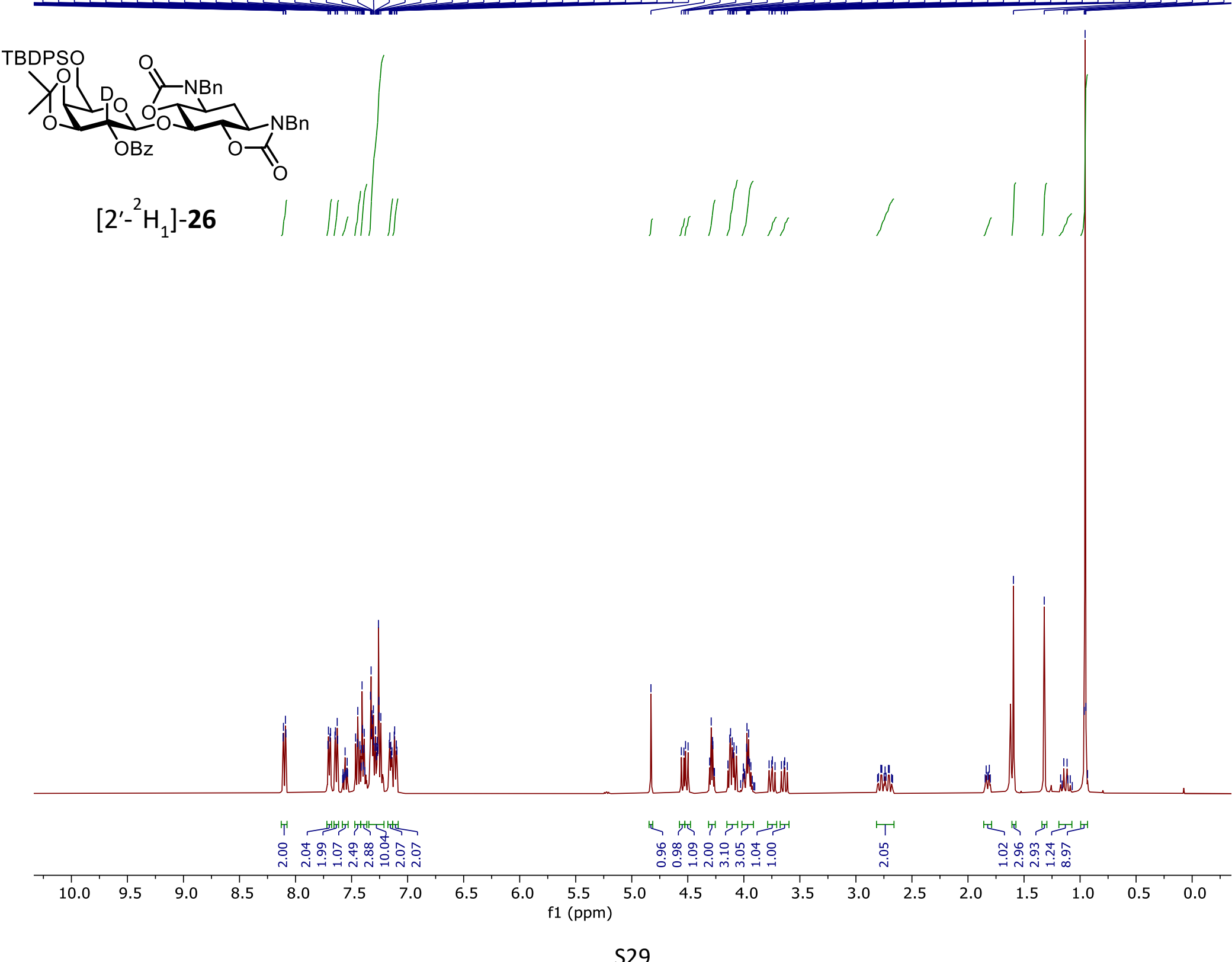




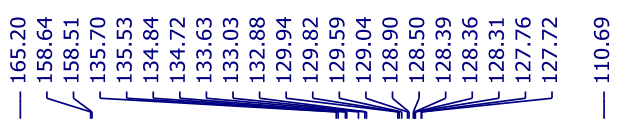

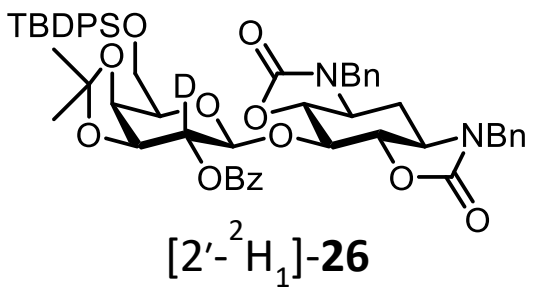

$\infty$
$\infty$
$\infty$
$\infty$

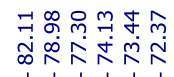

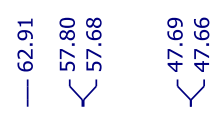

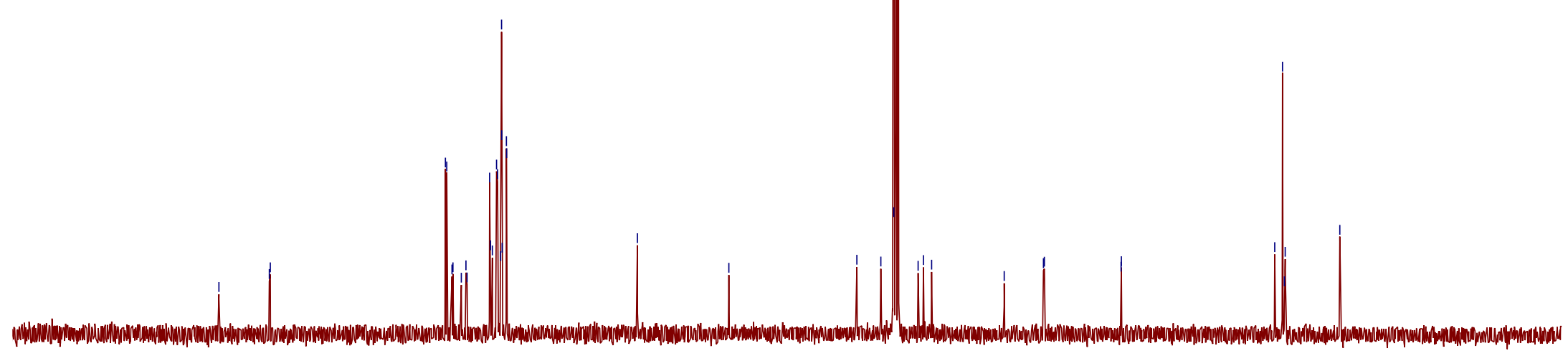

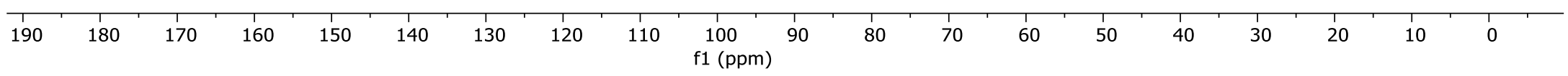

S30 


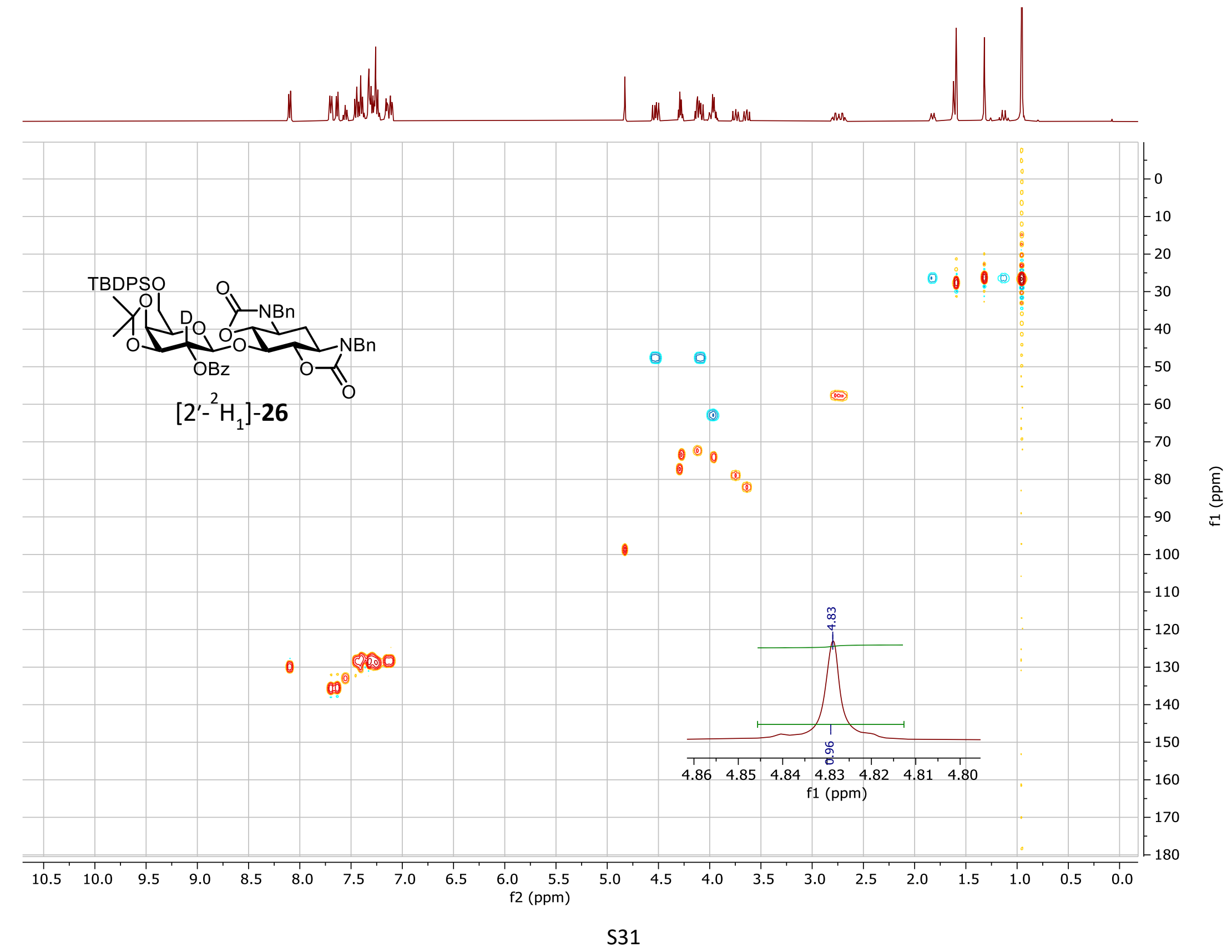




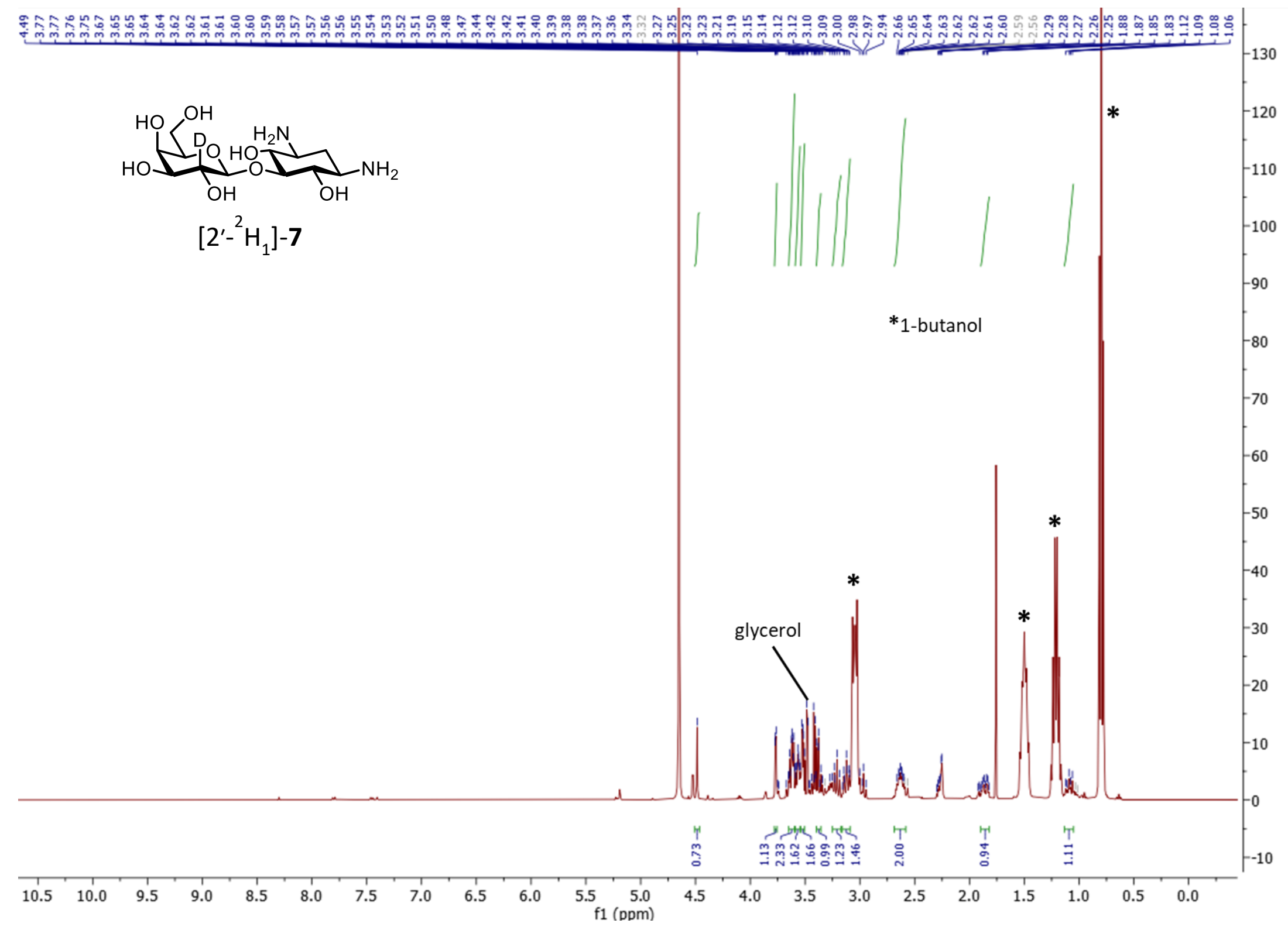




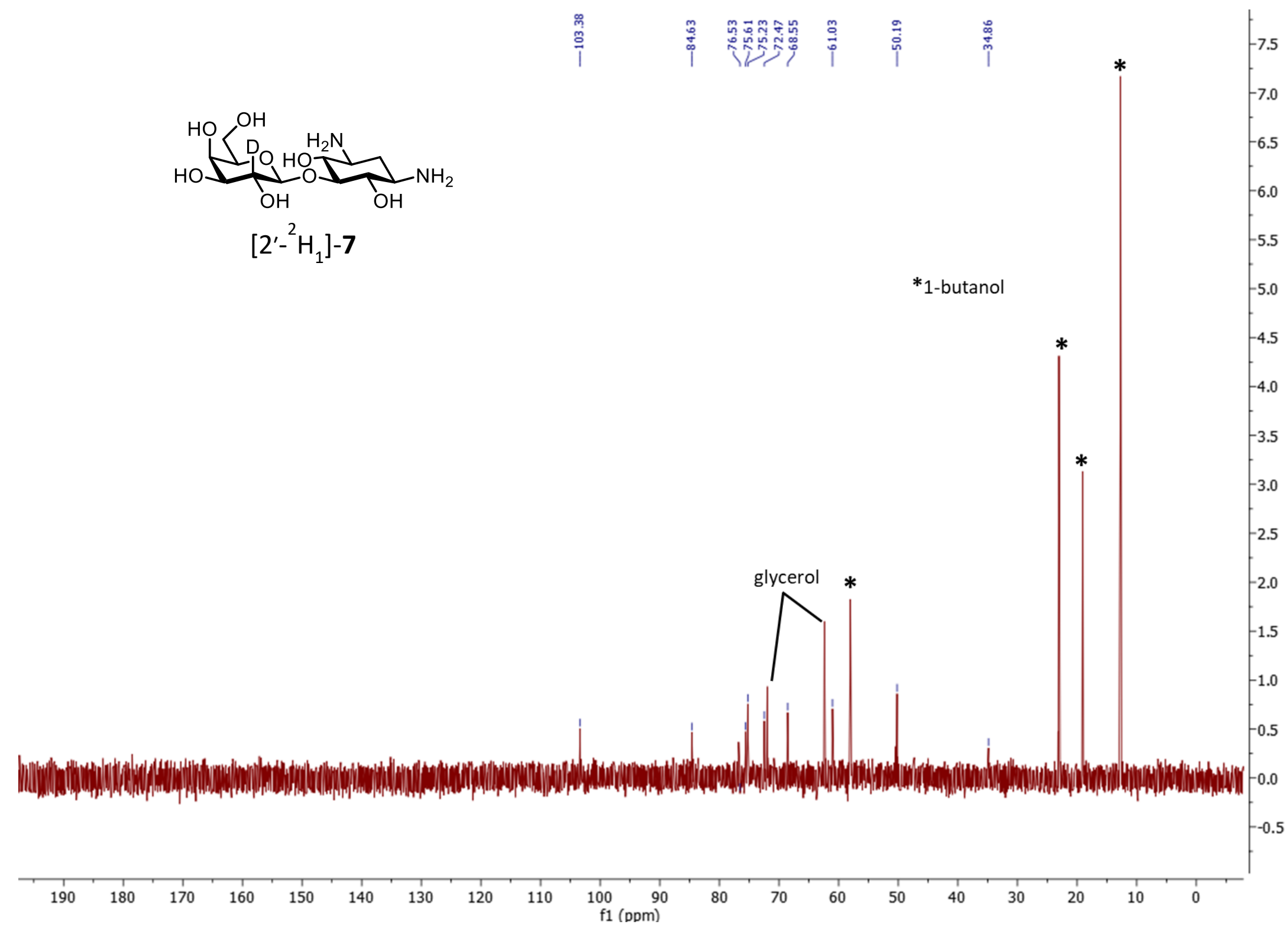




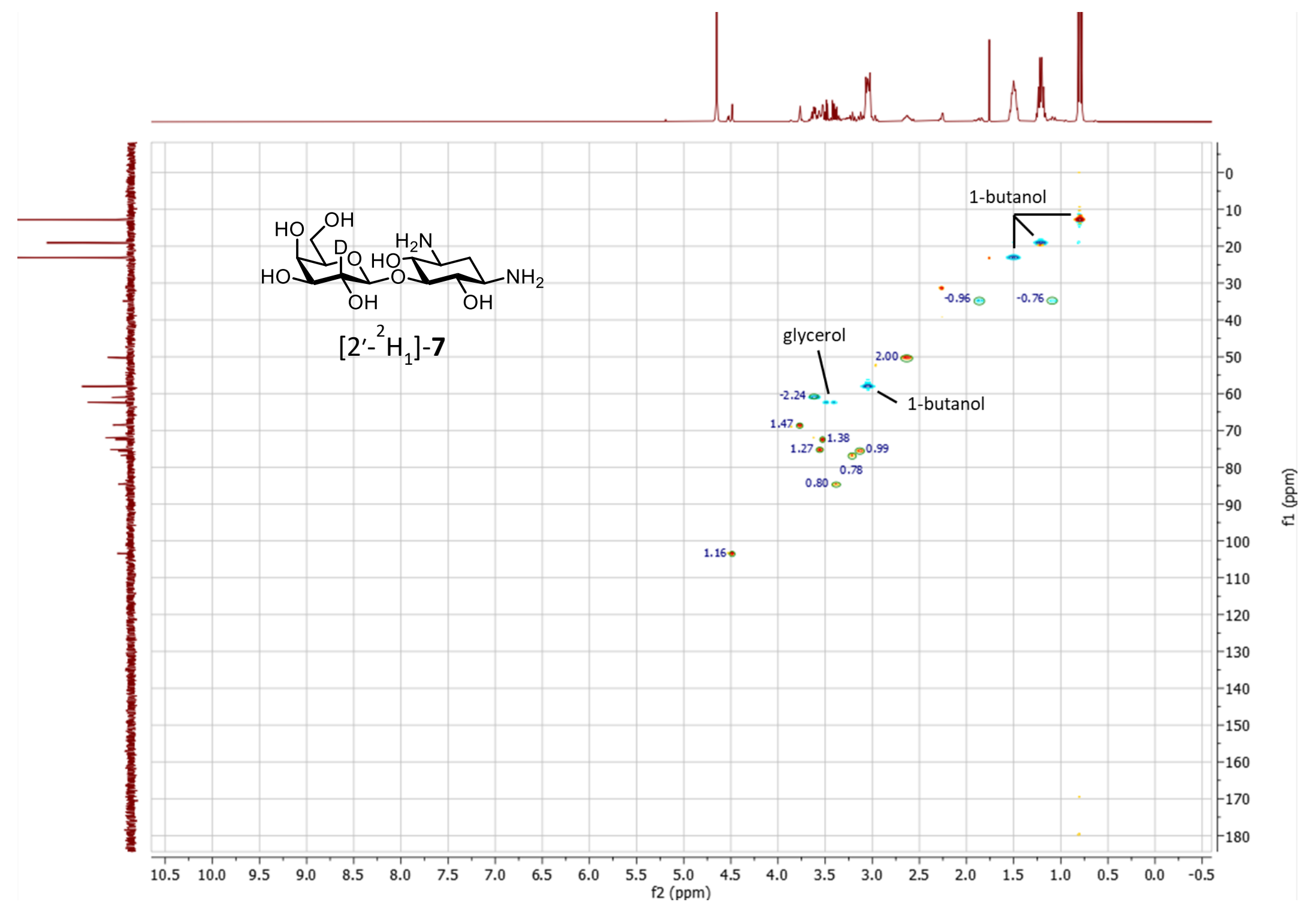




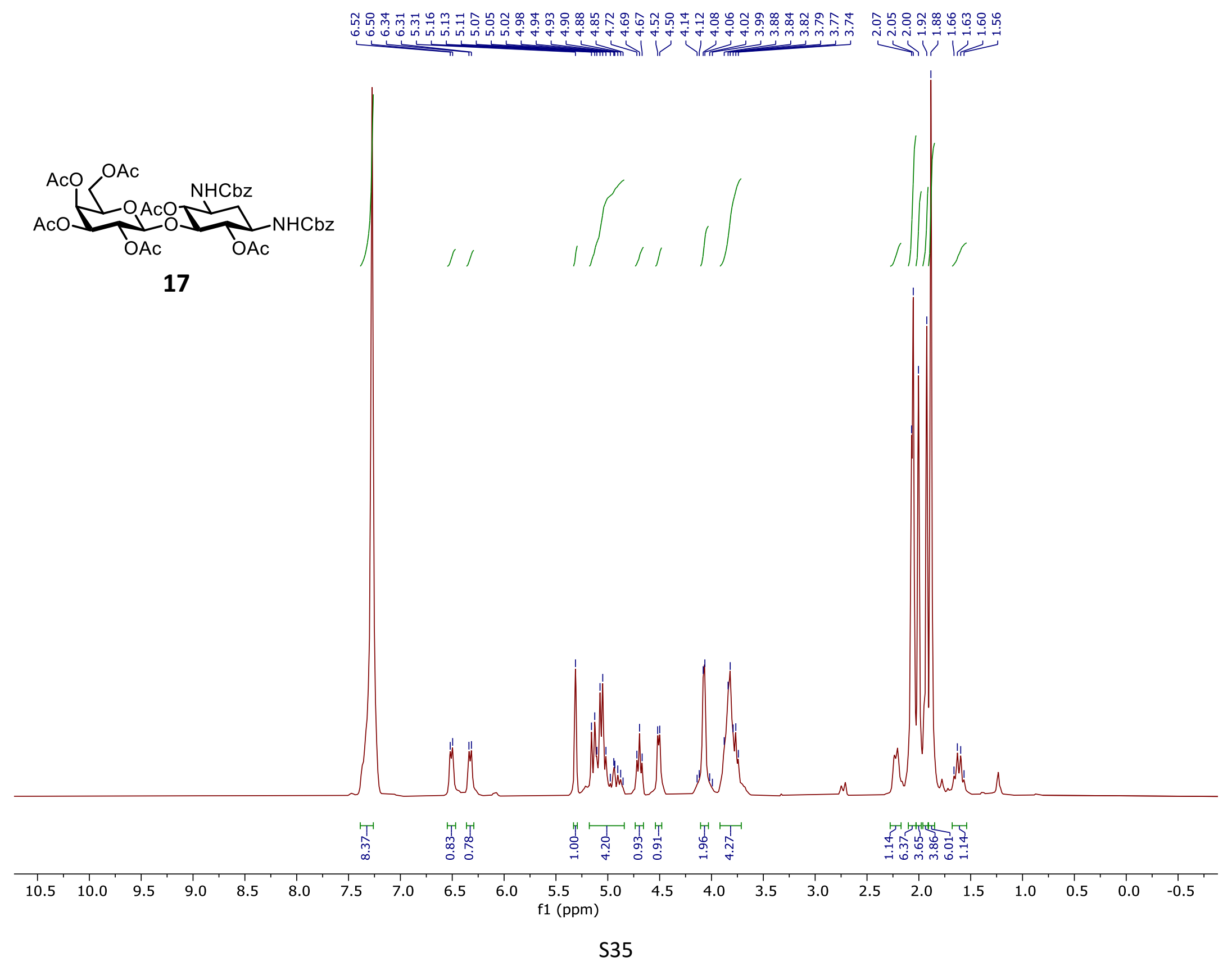




\begin{tabular}{|c|c|c|c|c|c|c|c|}
\hline 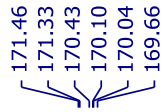 & 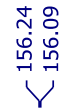 & 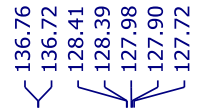 & $\begin{array}{l}\infty \\
0 \\
\stackrel{0}{0} \\
0 \\
1\end{array}$ & 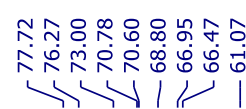 & 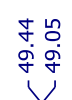 & $\underset{\infty}{\infty}$ & 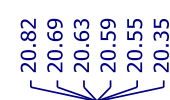 \\
\hline
\end{tabular}

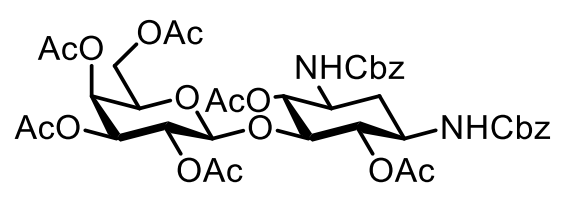

17

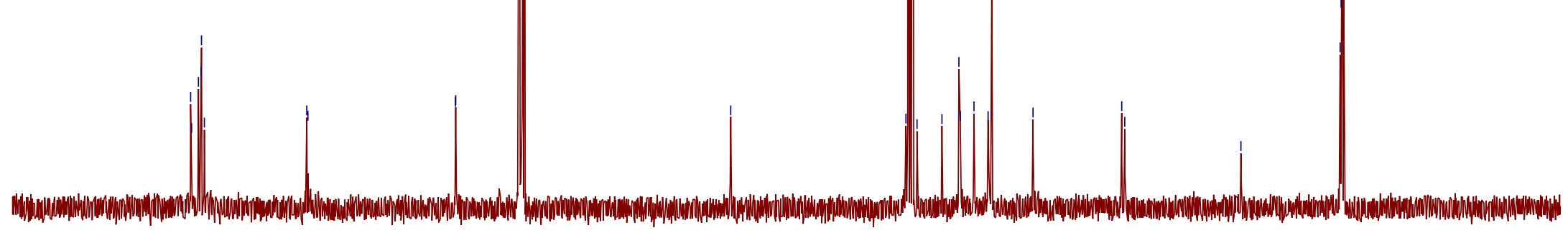

$190 \quad 180$

$170 \quad 160 \quad 150$

140

$130 \quad 120$

$110 \quad \begin{array}{r}100 \\ \mathrm{f} 1(\mathrm{ppm})\end{array}$ 


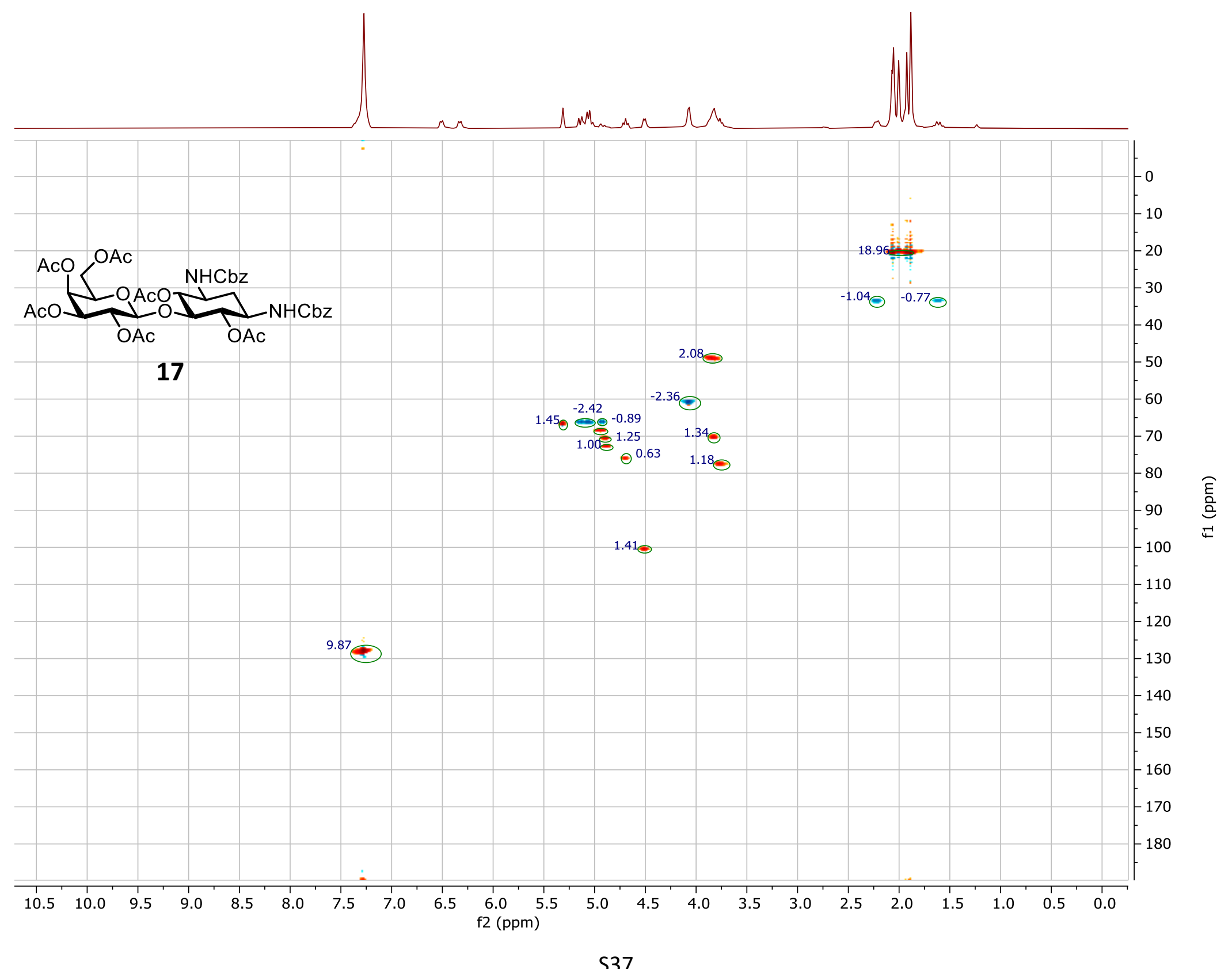




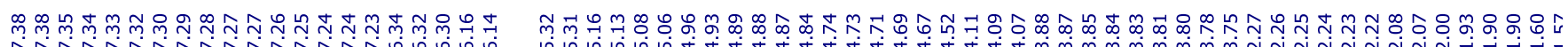
M

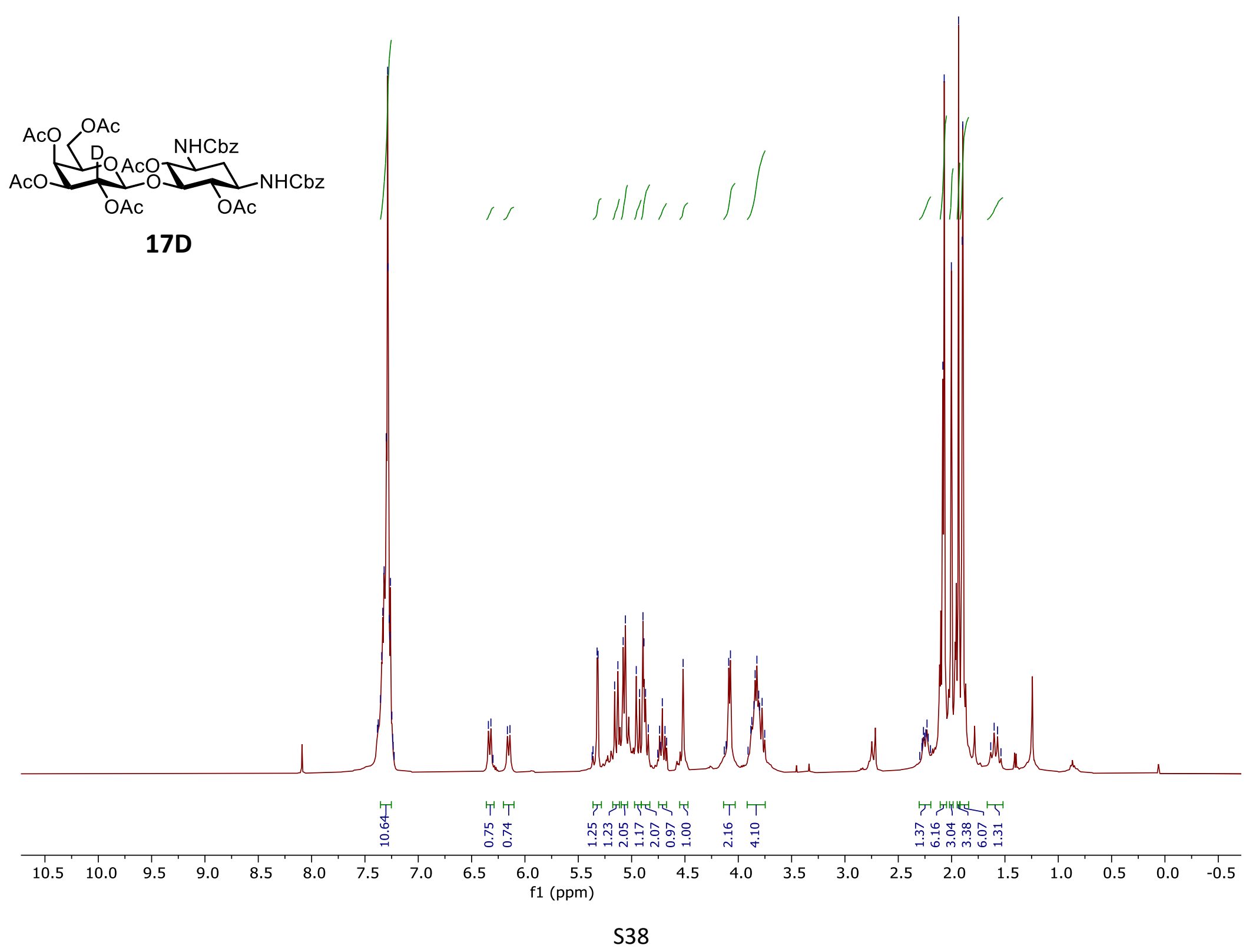




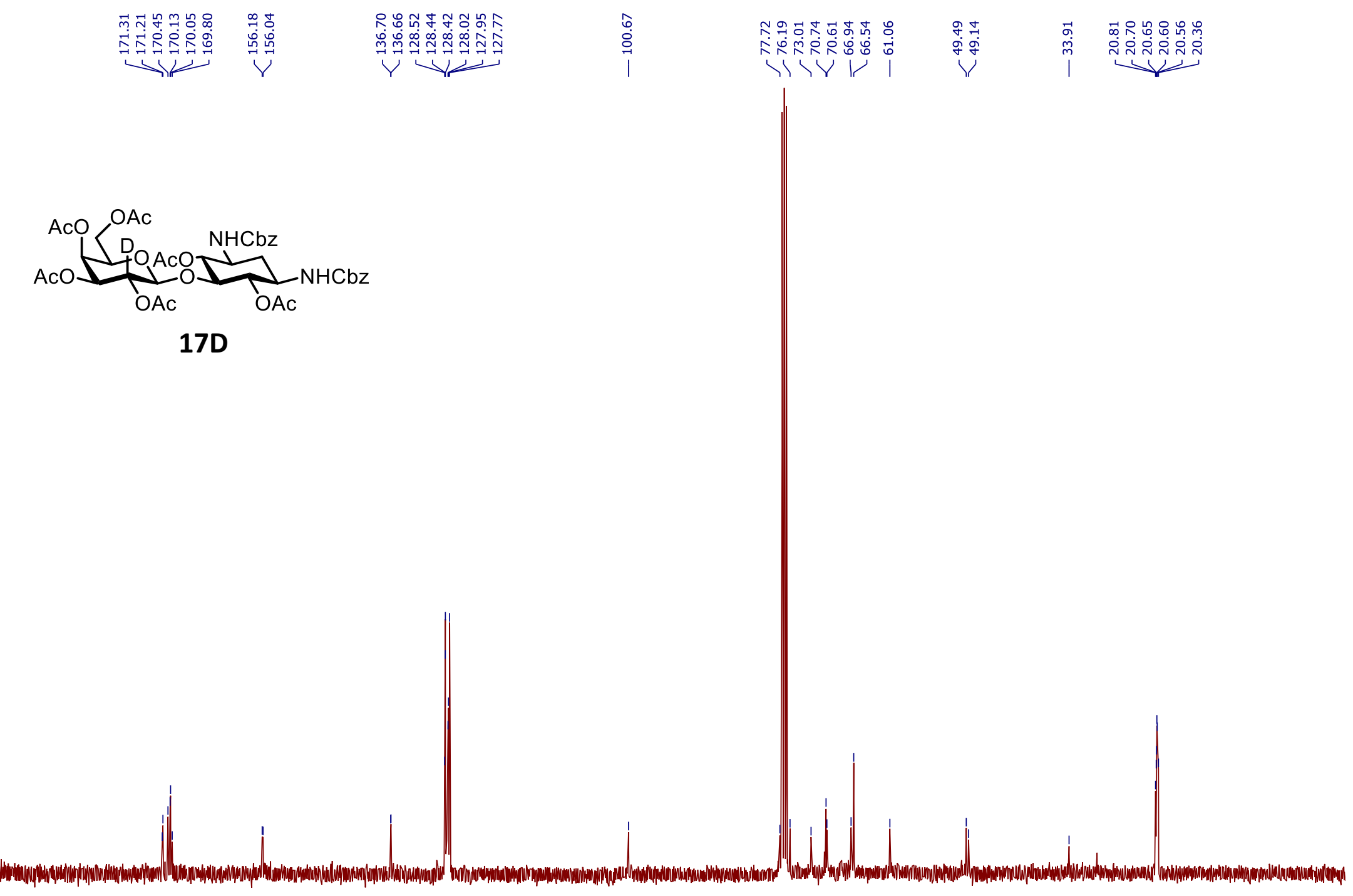

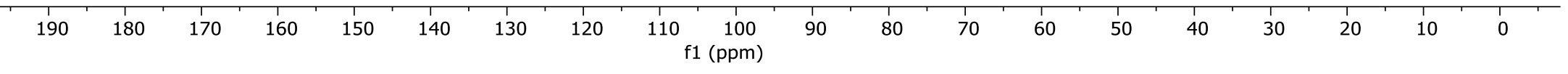




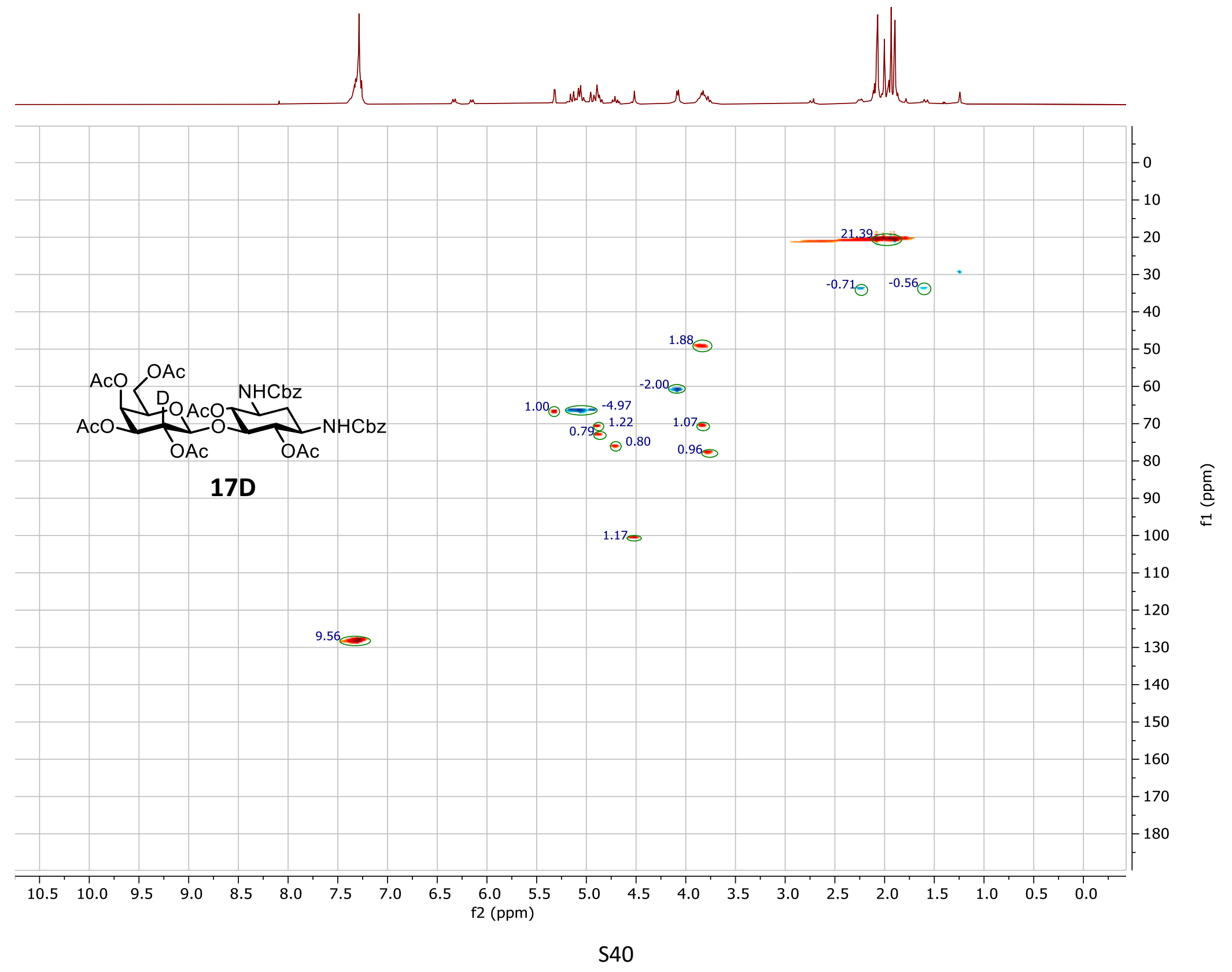




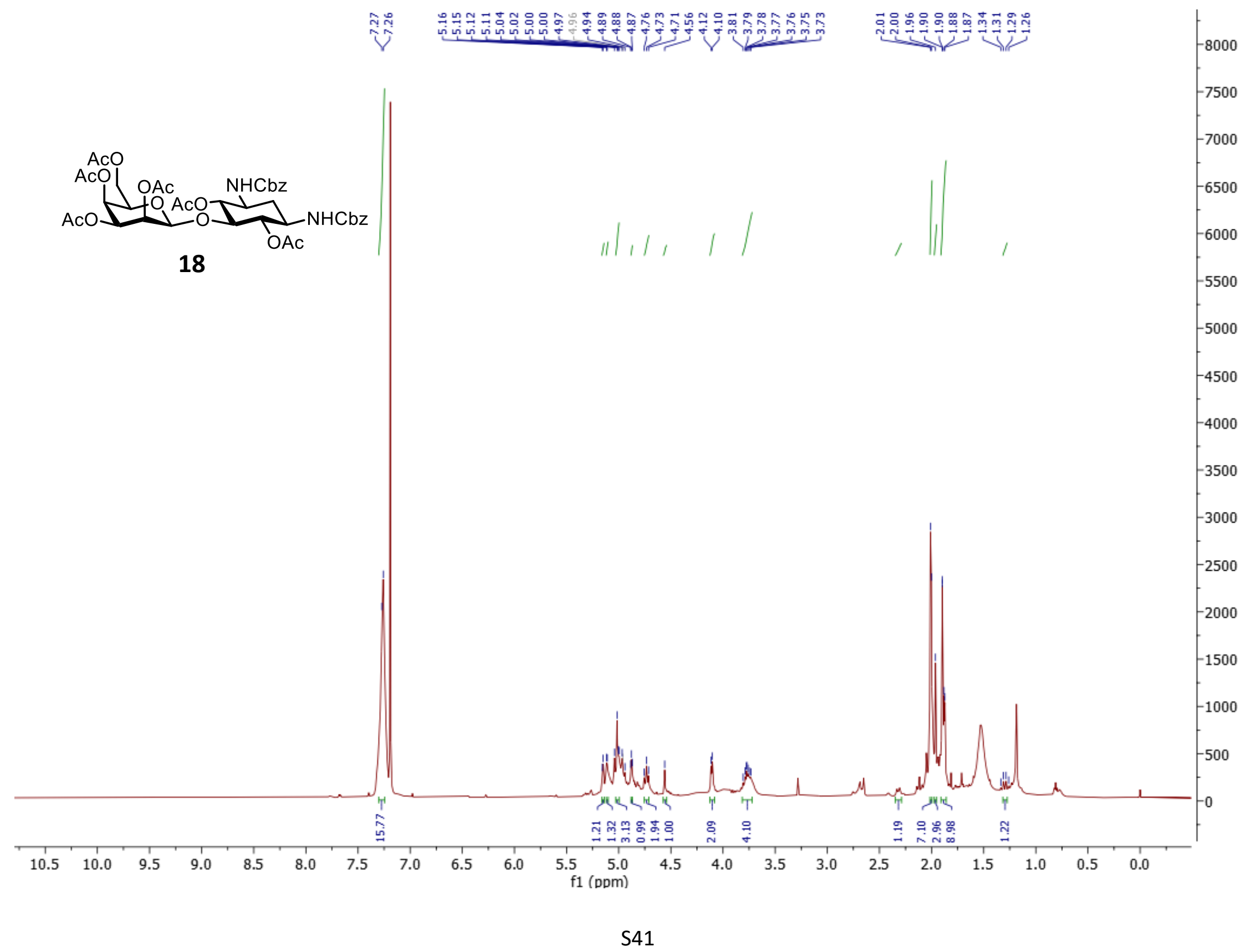




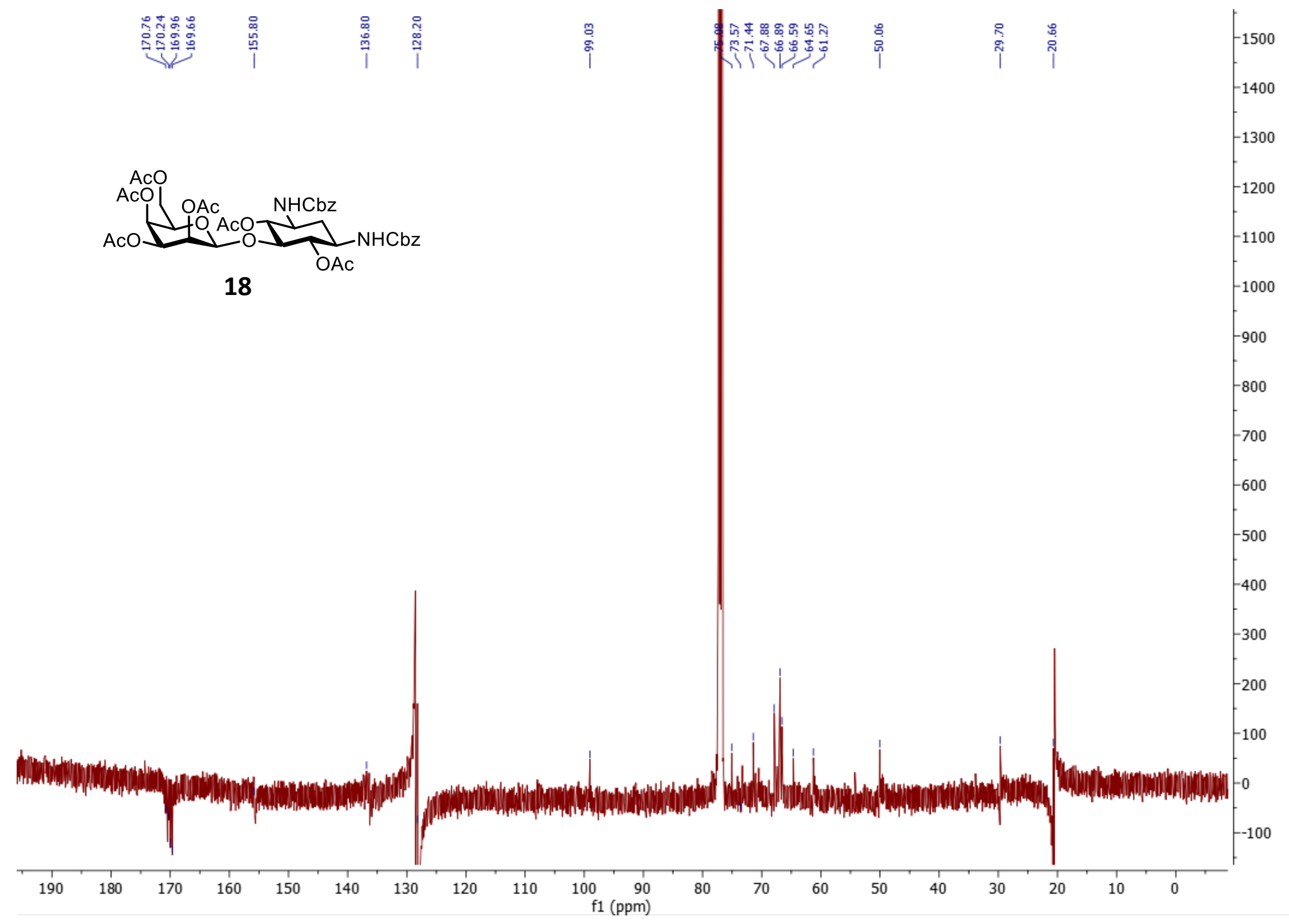




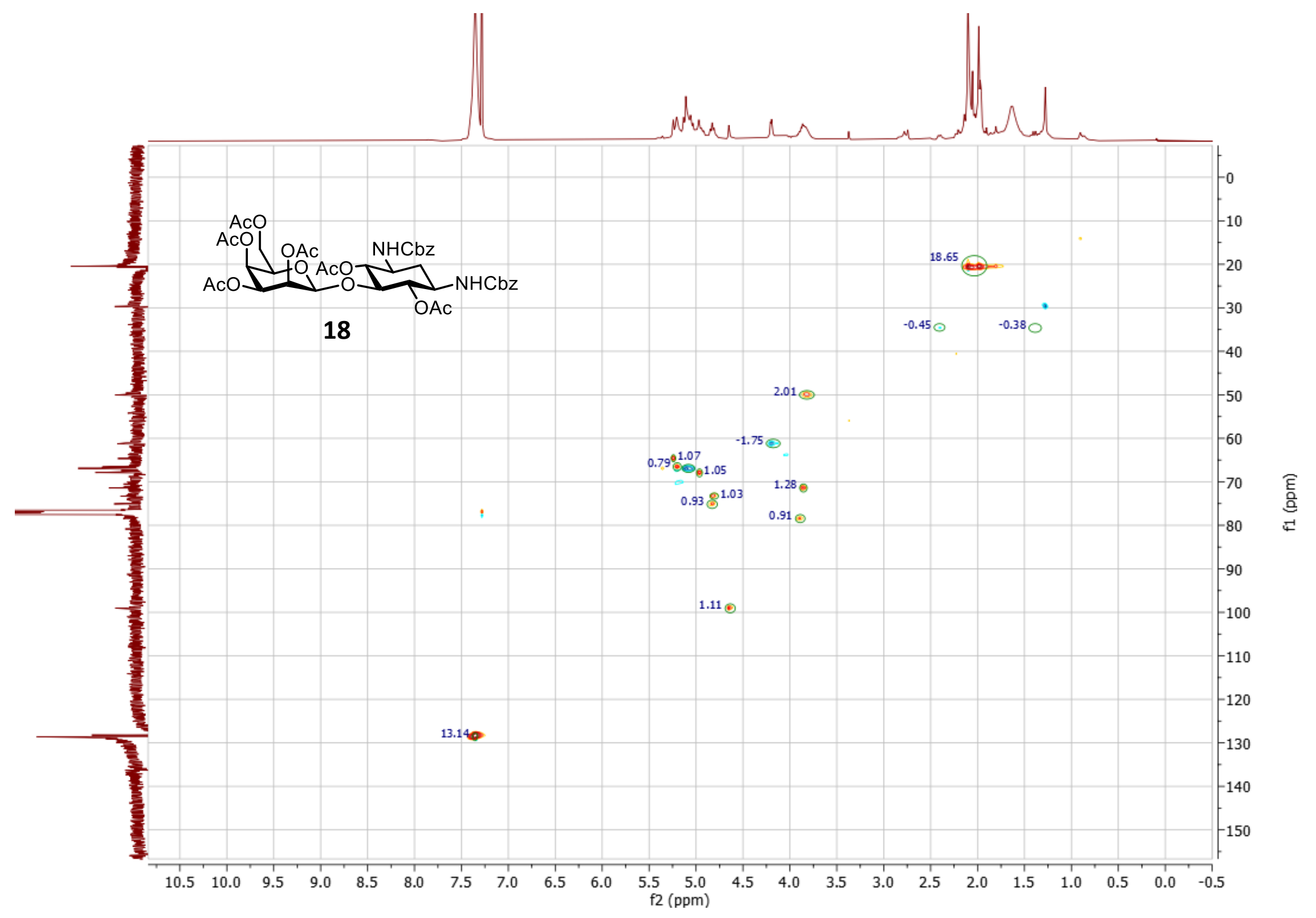




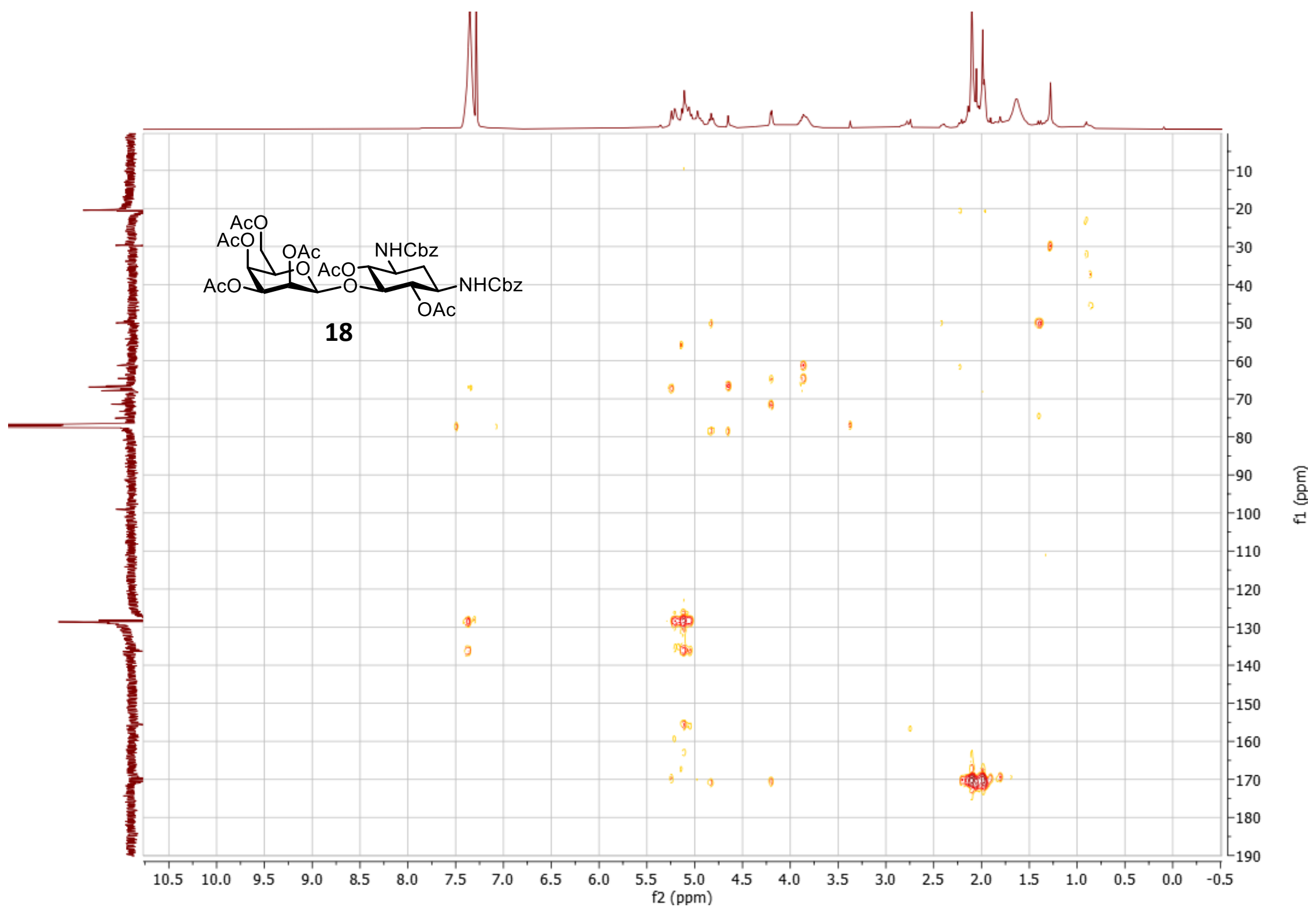

S44 